\title{
HTLV-1 Rex: the courier of viral messages making use of the host vehicle
}

\section{Kazumi Nakano* and Toshiki Watanabe*}

Laboratory of Tumor Cell Biology, Department of Medical Genome Sciences, Graduate School of Frontier Sciences, The University of Tokyo, Tokyo, Japan

\section{Edited by:}

Renaud Mahieux, Ecole Normale

Superieure de Lyon, France

Reviewed by:

Madeleine Duc Dodon, Institut

National de la Santé et de la

Recherche Médicale, France

Patrick Green, The Ohio State

University, USA

\section{${ }^{*}$ Correspondence:}

Kazumi Nakano and Toshiki Watanabe, Laboratory of Tumor Cell Biology, Department of Medical Genome

Sciences, Graduate School of Frontier Sciences, The University of Tokyo, 4-6-1, Shirokanedai, Minato-ku,

Tokyo 108-8639, Japan.

e-mail: nakanokz@ims.u-tokyo.ac.jp;

tnabe@ims.u-tokyo.ac.jp
The human T-cell leukemia virus type 1 (HTLV-1) is a retrovirus causing an aggressive T-cell malignancy, adult T-cell leukemia (ATL). Although HTLV-1 has a compact RNA genome, it has evolved elaborate mechanisms to maximize its coding potential. The structural proteins Gag, Pro, and Pol are encoded in the unspliced form of viral mRNA, whereas the Env protein is encoded in singly spliced viral mRNA. Regulatory and accessory proteins, such as Tax, Rex, p30II, p12, and p13, are translated only from fully spliced mRNA. For effective viral replication, translation from all forms of HTLV-1 transcripts has to be achieved in concert, although unspliced mRNA are extremely unstable in mammalian cells. It has been well recognized that HTLV-1 Rex enhances the stability of unspliced and singly spliced HTLV-1 mRNA by promoting nuclear export and thereby removing them from the splicing site. Rex specifically binds to the highly structured Rex responsive element (RxRE) located at the $3^{\prime}$ end of all HTLV-1 mRNA. Rex then binds to the cellular nuclear exporter, CRM1, via its nuclear export signal domain and the Rex-viral transcript complex is selectively exported from the nucleus to the cytoplasm for effective translation of the viral proteins. Yet, the mechanisms by which Rex inhibits the cellular splicing machinery and utilizes the cellular pathways beneficial to viral survival in the host cell have not been fully explored. Furthermore, physiological impacts of Rex against homeostasis of the host cell via interactions with numerous cellular proteins have been largely left uninvestigated. In this review, we focus on the biological importance of HTLV-1 Rex in the HTLV-1 life cycle by following the historical path in the literature concerning this viral post-transcriptional regulator from its discovery to this day. In addition, for future studies, we discuss recently discovered aspects of HTLV-1 Rex as a post-transcriptional regulator and its use in host cellular pathways.

Keywords: HTLV-1 Rex, retroviruses, post-translational regulator, CRM1, importin $\beta$, B-23, HTLV-2, HIV-1 Rev

\section{INTRODUCTION}

Human T-cell leukemia virus type 1 (HTLV-1) is widely accepted as the causative agent of adult T-cell leukemia (ATL) and was discovered almost a decade after the recognition of ATL as a disease (Takatsuki, 2005). By the early 1970s, many clinicians recognized the existence of a new type of human leukemia/lymphoma; however, an official description of ATL did not appear until 1977 in Kyoto, Japan. In 1979, HTLV-1 was confirmed in the United States (Gallo, 2005), and reported as the first human retrovirus (Poiesz et al., 1980, 1981). Soon after the discovery of HTLV-1, a retrovirus was also isolated from ATL patients in Japan and named adult T-cell leukemia virus (ATLV; Yoshida et al., 1982). It was then confirmed that ATLV and HTLV-1 were the same virus and the description was modified thereafter to indicate that ATL is caused by HTLV-1 (Popovic et al., 1982, 1983).

The genomic structure of the HTLV-1 provirus was thoroughly investigated and published by Seiki et al. (1983), which accelerated studies in biochemical and molecular aspects of HTLV-1 in the late 1980s and resulted in the first review on the molecular biology of HTLV-1 in 1995 (Franchini, 1995). Generally, RNA viruses have evolved elegant mechanisms to maximize coding potential and to precisely regulate the expression of encoded genes. Overlapping reading frames, internal ribosome entry sites, alternative splicing, sub-optimal Kozak sequences, and ribosomal frame shifting are among the varied mechanisms used to maximize genomic coding potential and regulate expression of specific viral genes (Balvay et al., 2007). HTLV-I has a compact genome RNA of 8685 nucleotides with two long terminal repeats (LTR) located at the $5^{\prime}$ and $3^{\prime}$ ends that function as the viral promoter. HTLV-1 encodes more than 10 open reading frames (ORFs) by employing several mechanisms to achieve appropriate and ordered expression of these genes, including alternative splicing and programmed ribosomal frame-shifting (PRF). In particular, gag and pol are separated by pro, which overlaps both the $3^{\prime}$ end of gag and $5^{\prime}$ end of pol. The protein precursors, Gag-Pro and Gag-Pro-Pol, share a common Gag initiator codon located at the $5^{\prime}$ end of gag, and expression is translationally regulated by an in-frame readthrough and PRF. PRF is a mechanism frequently used by viruses to alter the translational reading frame by shifting the ribosome at a slippery site (Theis et al., 2008). The HTLV-1 RNA genome has a -1 PRF at nucleotide 1718 and another at nucleotide 2245. Moreover, HTLV-1 RNA genome contains two major splice sites. Unspliced HTLV-1 RNA yields Gag, Pro, and Pol proteins and the singly spliced RNA produces Env, whereas the functional proteins derived from the $\mathrm{pX}$ region can be translated only from doubly spliced mRNA. 
The $3^{\prime}$ end of the HTLV-1 genome was named the $\mathrm{pX}$ region at the time the genomic structure of this virus was determined, since the function of this region was unclear. Deciphering the overlapped ORFs in the $\mathrm{pX}$ region allowed us to examine the encoded regulatory and accessory proteins of HTLV-1 in the $\mathrm{pX}$ region and newly discovered findings of wide-ranged functions of those viral proteins involved in the host cellular pathways have been quickly accumulated. Information concerning the function of HTLV-1 accessory proteins including Rex in the regulation of viral replication has been accumulated and updated during the last decade (Johnson et al., 2001; Franchini et al., 2003; Kashanchi and Brady, 2005; Taylor and Nicot, 2008; Kannian and Green, 2010). As a retrovirus, HTLV-1 is composed of only RNA genome that contains all the information necessary for self-replication; thus, the expression of viral genes entirely relies on the host transcriptional and translational machinery. Besides the structural proteins Gag, Pro, Pol, and Env, HTLV-1 encodes several unique regulatory and accessory proteins, such as Tax, Rex, P30II, p12, p13, and HTLV-1 basic leucine zipper factor protein (HBZ) coded in antisense ORF. Here we start this review of HTLV-1 Rex by introducing the functions of all viral accessory proteins before focusing on Rex, since these proteins function in concert to achieve successful infection and replication of HTLV-1 in the host cell. Thus, understanding the overall viral mechanism is necessary to understand the functional importance of Rex in the HTLV-1 life cycle.

\section{SCHEDULED AND CONCERT FUNCTIONS OF VIRAL PROTEINS FOR REGULATION OF VIRAL EXPRESSION}

HTLV-1 has two major transcriptional regulators, Tax and Rex. Tax is a strong trans-activator of HTLV-1 LTR promoter, which enhances the expression of integrated HTLV-1 proviruses (i.e., viral replication) during the early phase of infection. Tax also has a significant influence on host signal transduction, gene expression, and cell cycle regulation by interacting with various cellular proteins and plays a major role in immortalization and leukemogenesis of the host T-cells (Matsuoka and Jeang, 2007; Boxus et al., 2008). On the other hand, it is also well recognized that Tax is expressed only during the early phase of infection and not expressed, at least not at a detectable level, thereafter. Consequently, it remains unclear how the "influence" of Tax is maintained for decades and triggers transformation of infected T-cells.

Rex is an mRNA binding protein, which specifically binds to the Rex responsive element ( $\mathrm{RxRE}$ ) and acts as a post-transcriptional regulator of HTLV-1 mRNA. Since RxRE locates to the U3 and R regions, all HTLV-1 transcripts (i.e., unspliced, singly spliced, and doubly spliced mRNA) have RxRE. The most important function of Rex is selectively binding to unspliced and partially spliced HTLV-1 mRNA in the nucleus and quickly exporting them to the cytoplasm, thereby preventing further splicing and enhancing effective translation of the structure proteins (Hidaka et al., 1988; Adachi et al., 1990, 1992; Hamaia et al., 1997).

A second HTLV-1 RNA binding protein, p30II, specifically binds to doubly spliced tax/rex mRNA and retains it in the nucleolus. Therefore, p30II reduces Tax and Rex expression levels (and thus, overall viral activity), which eventually leads the virus to enter the latent period (Nicot et al., 2004; Ghorbel et al., 2006;
Sinha-Datta etal., 2007; Bai et al., 2010). Rex directly binds to p30II and rescues tax/rex mRNA retention by $\mathrm{p} 30 \mathrm{II}$ to promote viral replication (Sinha-Datta et al., 2007); thus, switching between replication and latency is modulated by $\mathrm{p} 30 \mathrm{II}$ and Rex interactions. In addition, p30II interacts with a number of cellular proteins and represses expression from HTLV-1 LTR by binding to p300, an important co-activator of LTR, probably by competing with Tax (Michael et al., 2006). This viral protein enhances the transforming activity of cMyc through interactions with a transforming co-activator, TIP60 (Awasthi etal., 2005). Recently, p30II was reported to enhance inappropriate DNA repair (Baydoun et al., 2011). The authors speculated that this new role of p30II may result in accumulation of DNA lesions during transformation of an infected cell. Anupam et al. (2011) also suggested an important role of p30II in enhancement of cellular survival under DNA damage through modulation of ataxia telangiectasia mutated (ATM) level, which is a key regulator of the cell cycle checkpoint initiated by a double-strand DNA break. The authors also demonstrated that REG $\gamma$, which stimulates the proteolytic activity of the $20 \mathrm{~S}$ core proteasome independent of ubiquitination and ATP, unexpectedly enhanced p30II expression. Overall, p30II has multiple functions via interactions with both viral proteins/transcripts and cellular proteins and maintains a balance between viral latency and spread, as well as between cellular survival and transformation.

The small HTLV-1 accessory proteins, p12 and p13, are not essential for viral replication, but they play important roles in escaping from the host immune system and transformation of infected T-cells (Koralnik et al., 1993; Nicot et al., 2005). Finally, HBZ, a product of the antisense strand of HTLV-1 RNA genome, is known to promote viral replication and cellular proliferation (Matsuoka and Jeang, 2011) and induces T-cell lymphoma and chronic inflammation in vivo (Satou et al., 2011). The importance of this antisense-coded protein in the viral life cycle remains vague, although Arnold et al. (2006) showed that HBZ was dispensable for cellular immortalization in vitro, whereas it enhanced viral infectivity in vivo in a rabbit model. A new perspective of this antisense gene-coded product as a non-coding RNA was recently proposed, since HBZ has not been observed at detectable levels in HTLV-1 carriers and ATL patients, and a large portion of $h b z$ mRNA was shown to accumulate in nucleus (Rende et al., 2011).

After HTLV-1 entry and integration into the host human genome, proviral expression is initiated and the viral regulatory/accessory proteins function in concert with a precise schedule. Such well-organized regulation of HTLV-1 expression has been investigated by many researchers in the field of molecular and cellular virology and it was also recently confirmed by kinetic calculations (Corradin et al., 2010). Figure 1 shows the time-course of HTLV-1 expression postinfection. Expression of the HTLV-1 provirus relies entirely on the host cell machinery and during the initial stage of infection, the viral mRNA is fully spliced to tax/rex mRNA. Since Tax has a stronger Kozak sequence than Rex, translation of Tax is initially superior to that of Rex (Green and Chen, 1990). Tax boosts transcription by LTRs and Rex gradually accumulates. Once a sufficient level of Rex is pooled in the host cell, Rex blocks splicing of viral mRNA and exports the unspliced and singly spliced viral mRNA to the cytoplasm for selective translation of Gag, Pro, Pol, and Env, resulting in active 


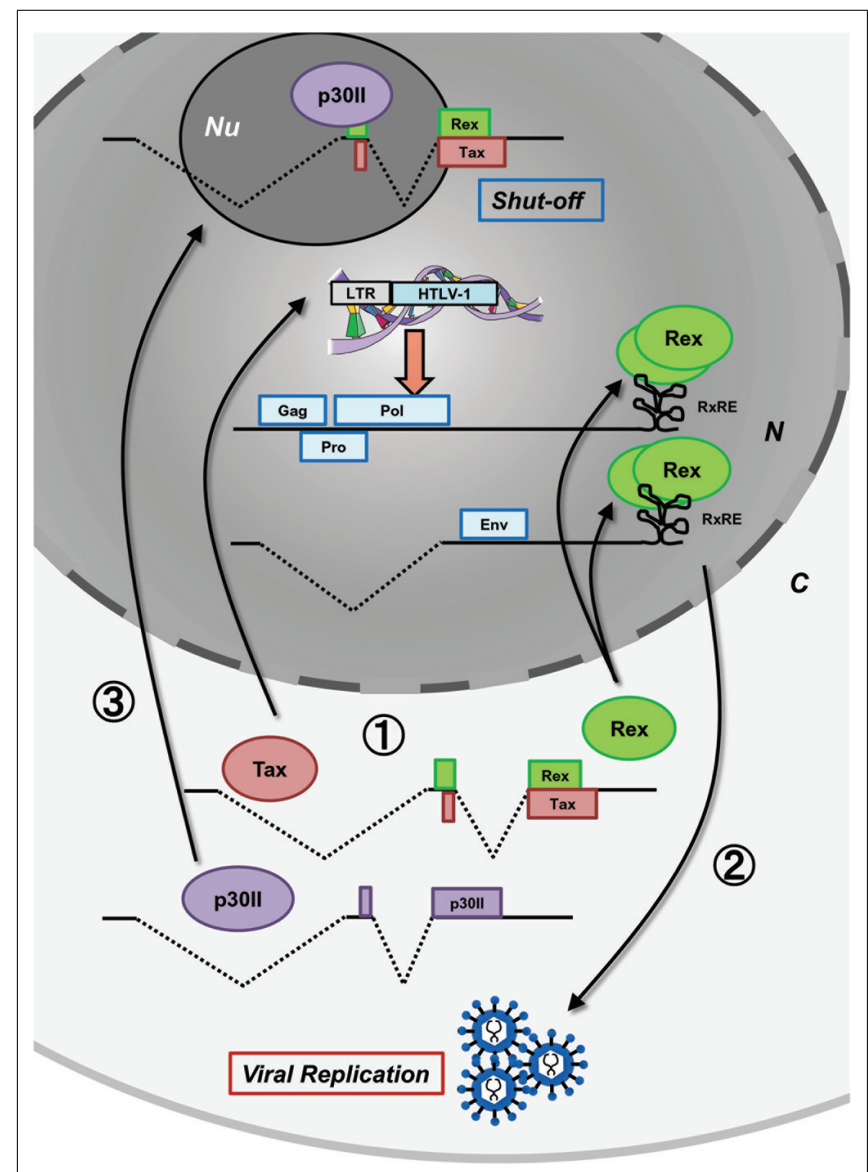

FIGURE 1 | Concerted functions of viral proteins for HTLV-1 expression. Postinfection, the HTLV-1 provirus expresses viral proteins at appropriate times to control the early productive phase and the late shut-down phase leading to latency in the HTLV-1 life cycle. At the very beginning, without Rex, the viral transcripts are fully spliced and thus, Tax and Rex are selectively translated (stage 1). Tax transactivates HTLV-1 LTR promoter activity, whereas Rex inhibits splicing and actively exports the unspliced and singly spliced viral mRNA from the nucleus resulting in the expression of structural proteins and production of viral particles (stage 2). In the late phase, p30ll from a minor, doubly spliced transcript binds to tax/rex mRNA and confines it to the nucleoli (stage 3 ) resulting in decreased Tax/Rex protein levels leading to latency. N, nucleus; C, cytoplasm; Nu, nucleolus.

viral replication. Selective nuclear export of unspliced and partially spliced viral mRNA by Rex eventually reduces the export of fully spliced tax/rex mRNA, resulting in a decrease in Tax expression. Finally, p30II, with a strong nucleolar localization signal (NoLS), is expressed from the minor doubly spliced viral mRNA and retains tax/rex mRNA in the nucleoli, thus preventing their expression and avoiding immune evasion to initiate latency. The time course of HTLV-1 expression was thoroughly investigated by Li et al. (2009) in HTLV-1-expressing 293T cells. Such time-lagged operations of the positive (Tax and Rex) and negative (p30II) regulators of HTLV-1 promotes the early infectious phase followed by a rapid shut-down in the late infectious phase to escape from the host immune surveillance against pathogens (Figure 1).

During the course of viral expression, the small viral accessory proteins $\mathrm{p} 13$ and $\mathrm{p} 12$ also function to optimize the cellular environment for the viral spread and facilitate viral persistence in infected cells. p13, a short isoform corresponding to the C-terminal 87 aa of p30II is localized primarily in the mitochondrial inner membrane and increases mitochondrial permeability to $\mathrm{K}^{+}$and activates the electron transport chain. This results in increased mitochondrial production of reactive oxygen species, which induces genetic instability and apoptosis (Silic-Benussi et al., 2010a,b; Biasiotto et al., 2010). p13 also localizes to the nucleus and is ubiquitinated by Tax for stabilization; thus, HTLV-1 balances viral expression and silencing through negative feedback (Andresen et al., 2011). The balance between T-cell activation and silencing is achieved by HTLV-1 p12 and p8, which are encoded in the singly spliced viral mRNA at minor splicing sites. p12, which mainly localizes to the endoplasmic reticulum (ER) and modulates T-cell activation and proliferation by interacting with the $\beta$ and $\gamma$ chains of the interleukin-2 receptor (IL-2R) and leading to activation of the Janus kinase/signal transducer and activator of transcription 5 (Jak/Stat5) signal transduction pathway to provide a mitogenic signal (Prooyen et al., 2010a,b). p12 also decreases surface expression of major histocompatibility complex I via proteasomal degradation, thus contributing to the rescue of HTLV-1-infected cells from being targeted by CTL. p12 also interacts with calreticulin and calnexin resulting in increased $\mathrm{Ca}^{2+}$ release from the ER and activation of the nuclear factor of activated T-cells (NFAT), a mitogenic pathway in T-cells. On the other hand, p8, which is cleaved from p12 in the ER, travels to the cell surface and induces T-cell anergy. p8 also increases cell-to-cell viral transmission through the formation of immunological synapses (Prooyen et al., 2010a,b).

HBZ was the first viral protein found to be encoded in the antisense ORF of HTLV-1. HBZ is known to interact with cAMP response element-binding protein 2 (CREB-2) and suppresses Taxmediated viral transcription. $\mathrm{HBZ}$ also enhances viral replication (Matsuoka and Jeang, 2011). On the other hand, previous reports demonstrated that HBZ expression does not affect the ability of HTLV-1 to immortalize T-lymphocytes in culture (Arnold et al., 2006), and that $h b z$ mRNA enhanced T cell proliferation in culture and transgenic mice (Satou et al., 2006). These reports proposed the possibility that HBZ proteins and $h b z$ mRNA may have different functions. Choudhary and Ratner (2011) demonstrated that $h b z$ mRNA destabilizes p30ii mRNA, thus increasing Tax expression. Rende et al. (2011) showed that $h b z$ mRNA remains in the nucleus and speculated that $h b z$ mRNA may have an important physiological role as a functional non-coding mRNA. Further investigations are necessary to clarify the involvement of $\mathrm{HBZ}$ and $h b z$ mRNA in the HTLV-1 life cycle.

Overall, the interactions and positive and negative feedbacks among HTLV-1 Tax, Rex, p30II, and HBZ control the activation and inhibition of HTLV-1 expression, whereas p13, p12, and p8 organize a cellular environment suitable for viral retention.

\section{HTLV-1 Rex: THE CONDUCTOR OF VIRAL POST-TRANSCRIPTIONAL EXPRESSION}

HTLV-1 Rex is a viral RNA binding protein of approximately $27 \mathrm{kDa}$ and is essential for nuclear export of viral mRNA. Rex is also known to stabilize and export unspliced and singly spliced 
viral mRNA that code structural proteins; thus, Rex is considered essential for viral replication (Inoue et al., 1986, 1987; Hidaka et al., 1988; Gröne etal., 1996). It has been speculated that Rex interacts with the host splicing machinery in the nucleus to prevent splicing and stabilizes unspliced and partially spliced viral mRNA. However, the exact molecular mechanisms have not been fully elucidated to date.

As a viral post-transcriptional regulator, Rex binds to the RxRE of the viral transcript with high affinity. The RxRE sequence spans $255 \mathrm{nt}$ from the U3 to $\mathrm{R}$ region of the $3^{\prime} \mathrm{LTR}$ and forms a stable secondary structure consisting of four stem loops (Ahmed et al., 1990). RxRE is not only a landmark for Rex binding, but it is also essential for optimal positioning of the polyA signal and polyA binding site in the HTLV-1 transcript, which are otherwise separated by the RxRE sequence (Ahmed et al., 1991). The cis-acting repressive sequence (CRS) is another regulatory sequence of HTLV-1 mRNA, located at both ends of HTLV-1 LTRs. Seiki et al. (1990) described the CRS in the U5 region for the first time and concluded that the CRS suppresses $\mathrm{R}$ activity, thereby enhancing RNA expression from the LTR. In agreement with their hypothesis, the authors demonstrated that the CRS in the U5 region significantly suppressed the expression of unspliced HTLV-1 mRNA only, but not spliced mRNA, since splicing within the $\mathrm{R}$ region removes the $\mathrm{U} 5$ element from the spliced mRNA. Interestingly, the function of Rex in protection of unspliced mRNA from splicing is CRS-independent. Thus, the CRS can be viewed as a post-transcriptional repressor, whereas Rex stabilizes unspliced viral RNA by directly interacting with the splicing machinery in addition to evacuating the unspliced viral mRNA to compartments not accessible to the splicing machinery. More recently, the other CRS in the $3^{\prime}$ LTR region overlapping the RxRE sequence was identified by King et al. (1998). They examined the functions of $5^{\prime}$ and $3^{\prime} \mathrm{CRSs}$ separately and clarified that $5^{\prime}$ CRS hampers nuclear export of only unspliced viral mRNA, whereas $3^{\prime}$ CRS does so for all spliced and unspliced viral mRNA. This is rather reasonable, since $5^{\prime} \mathrm{CRS}$ remains only in unspliced mRNA, whereas $3^{\prime} \mathrm{CRS}$ is conserved in all forms of viral mRNA. They also found that deletion of both CRSs induced the constitutive nuclear export of reporter transcripts independent of Rex. Recently, Li et al. (2012) demonstrated that nuclear export of unspliced gag/pol mRNA and singly spliced env mRNA of HTLV-1 was Rex-dependent, whereas that of alternatively spliced mRNA was not. According to their conclusion, the unspliced and singly spliced HTLV-1 mRNA, containing RxRE/CRS and a functional splice donor site, are nuclear-exported in a Rex/RxREdependent manner, whereas the fully spliced mRNA is not, even though it contains a $3^{\prime} \mathrm{RxRE} / \mathrm{CRS}$. Their results are somewhat different from those of Bai et al. (2012), who demonstrated that tax/rex mRNA was also nuclear-exported in a Rex/RxRE/CRM1dependent manner. All together, nuclear export of unspliced and spliced mRNA of HTLV-1 seems to be fine-tuned by nuclear retention activity of CRS and selective nuclear exporting activity of Rex.

Rex is a phosphoprotein; therefore, its activity is determined by the state of phosphorylation at the several serine/threonine residues (Kesic et al., 2009a). Adachi et al. (1990) demonstrated for the first time that Rex is activated by phosphorylation, since the treatment of an HTLV-1-infected cell line, HUT102, with a protein kinase $\mathrm{C}$ inhibitor, H-7 [1-(5-isoquinolinyl-sulfonyl)-2methylpiperazine], resulted in decreased levels of unsliced viral mRNA and Gag-p19 protein. They also determined Rex phosphorylation sites at S70, S177, and Th174 (Adachi et al., 1992), although the kinase(s) responsible for Rex phosphorylation have not yet been identified. Recently, Kesic et al. (2009a) thoroughly examined Rex phosphorylation sites by conducting phosphoryl mapping and discovered five other phosphorylation sites at Thr-22, Ser-36, Thr-37, Ser-97, and Ser-106. On the other hand, they were unable to confirm the phosphorylation of Ser-177 as reported by Adachi et al. (1992) and concluded that Rex has seven phosphorylation sites in total. They also evaluated the importance of each phosphorylation site by a reporter assay using RxREdependent HIV-1 p24 Gag expression plasmids and concluded that phosphorylation of Ser-97 and Thr-174 most significantly influenced the expression level of the reporter plasmid, i.e., the RxRE-dependent nuclear export of reporter mRNA by Rex.

The HTLV-1 Rex, a protein of $27 \mathrm{kDa}$, contains several functional domains which play essential roles to induce the function of Rex as a nuclear-cytoplasmic mRNA transporter. The locations and physiological importance of each Rex domain are well described in several review articles (Younis and Green, 2005; Baydoun et al., 2008). A highly basic N-terminal RNA-binding domain located within aa 1-19 is essential for RxRE binding. This domain also serves as a nuclear localization signal (NLS), as well as a binding domain for p30II. The nuclear export signal (NES) spans from aa 66 to 118. Rex binds to Exportin-1 (CRM1), a cellular nuclear export protein through the NES; thus, this domain is essential for Rex function. The multimerization domains are located at the N- and C-terminal ends of NES (aa 57-66 and 106124). The importance of NES and multimerization domains in Rex was well studied by Hakata et al. (1998, 2001). Based on a series of experiments investigating the interaction between CRM1 and Rex mutants in NES or in $\mathrm{N}^{\prime}$-multimerization domains, the authors found that NES is critical for interactions with CRM1. Thus, a multimer-deficient mutant Rex was translocated to the cytoplasm by CRM1; however, the multimer-deficient mutant Rex was not able to stabilize unspliced viral mRNA. Moreover, they revealed that rat CRM1 (rCRM1) was unable to support the function of Rex as an mRNA transporter because of its poor ability to induce multimerization of Rex, although rCRM1 can bind and export nuclear Rex proteins to the same extent as human CRM1. Accordingly, they concluded that the Rex protein needs to be both a multimerized and nuclear-exported to achieve its function, and that CRM1 was involved in multimerization and translocation of Rex. Recently, a stability domain was identified at the very end of the Rex C-terminus (aa 170-189; Kesic et al., 2009a,b; Xie et al., 2009). They showed that deletion of this segment resulted in a decreased half-life of Rex; however, the activity of Rex without the stability domain (SD), at least in translation from RxRE containing HIV-1 p24 gag mRNA, was not significantly influenced.

To regulate viral expression through host machinery, Rex interacts with several host cellular proteins (Figure 2). To date, interaction of Rex with the following cellular proteins have been confirmed: CRM1 as already mentioned, the heterogeneous nuclear ribonucleoprotein A1 (hnRNP A1), the splicing 


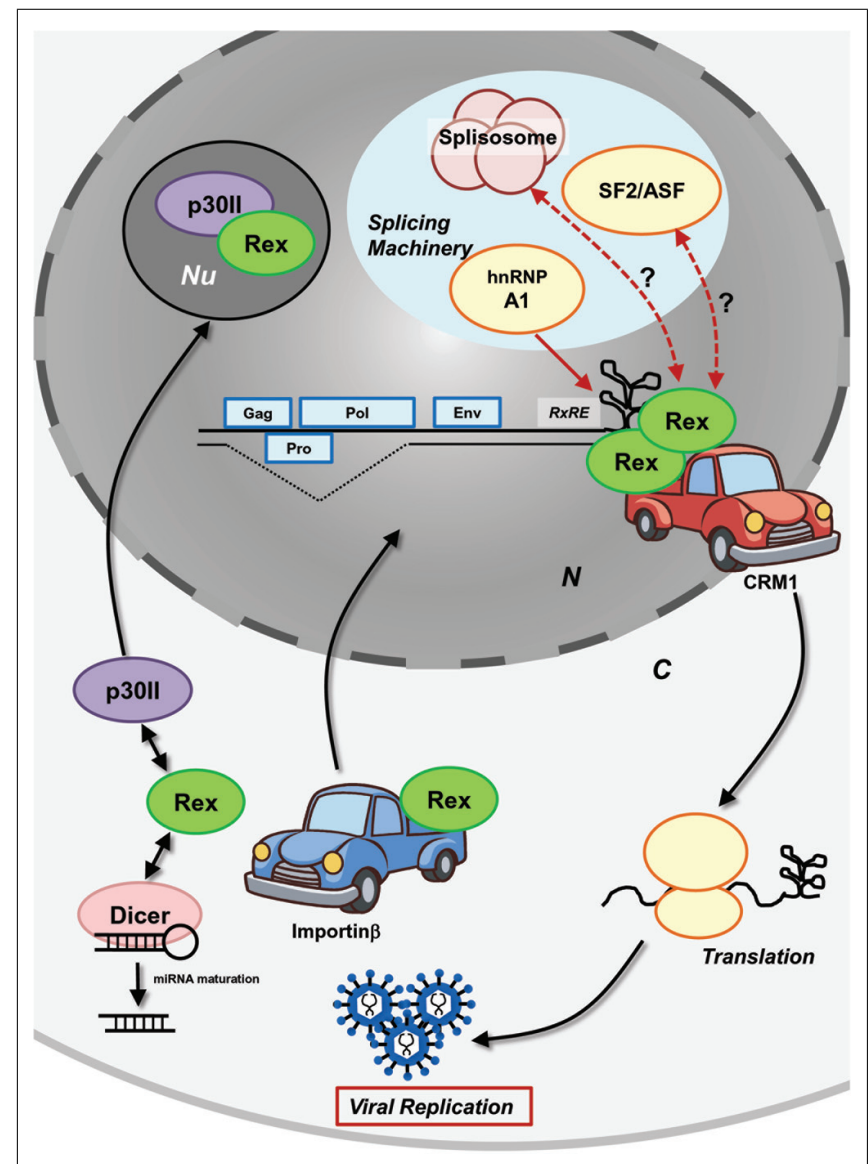

FIGURE 2 | Molecular mechanism of HTLV-1 Rex function. HTLV-1 Rex specifically binds to the RxRE motif of HTLV-1 transcripts. Rex also interacts with the cellular nucleocytoplasmic shuttling protein, CRM1, through its NES. Consequently, the Rex-viral mRNA complex is exported from the nucleus by CRM1. In the cytoplasm, Rex subjects viral transcripts to the cellular translational machinery to enhance viral production. Released Rex binds to importin $\beta$ via its NLS and returns to the nucleus by the importin complex shuttling activity. P30ll binds to Rex through its NLS and retains Rex in the nucleolus for suppression. Rex not only transports viral transcripts, but also inhibits splicing of viral mRNA that encode structural proteins. hnRNP A1, which governs the processing/splicing of pre-mRNA and transport of mature mRNA, was found to bind to RxRE in a competing manner against Rex. Another major splicing factor, SF2/ASF, was found to influence the processing of HTLV-1 mRNA (i.e., overexpression of SF2/ASF resulting in differential $\mathrm{pX}$ splice site utilization), although the direct physiological interaction to the viral proteins has not been examined. Recently, Rex was shown to directly interact with Dicer and inhibit its processing of shRNA to siRNA (Abe et al., 2010). Overall, interactions between Rex and other cellular mRNA processing proteins may lead to an unknown molecular mechanism of Rex in the inhibition of the splicing machinery. N, nucleus; C, cytoplasm; Nu, nucleolus.

factor SF2, importin $\beta$, and nucleolar protein B-23. hnRNPs are heterogeneous nuclear RNA (hnRNA) binding proteins associated with pre-mRNA in the nucleus that influence the processing/splicing of pre-mRNA and the transport of mature mRNA. hnRNP A1 was shown to bind to the RxRE sequence of HTLV-1 viral mRNA in competition with Rex (Duc Dodon et al., 2002). Suppression of hnRNP A1 expression in HTLV-1-infected C91PL cells resulted in increased Rex-dependent nuclear export of unspliced and singly spliced mRNA, as well as in accumulation of unspliced mRNA (Kress et al., 2005). The authors confirmed that hnRNP A1 inhibits the function of Rex in a dose-dependent manner and proposed that hnRNP A1 may enhance the splicing processes of viral mRNA. Moreover, the authors found that the basal level of hnRNP A1 is lower in HTLV-1-producing cell lines (C91PL, MT2, and HUT102) when compared with nonHTLV-1-infected T-cell lines (CBL and Jurkat), indicating that HTLV-1 may induce the down-regulation of hnRNP A1, which is not conducive to viral replication. Another major splicing factor, SF2/ASF, also influences the processing of HTLV-1 mRNA, although direct physiological interactions with viral proteins have not been examined (Princler et al., 2003). SF2/ASF is considered to be involved in all splicing reactions in the cell and plays a critical role in splice site selection in a concentration-dependent manner. Indeed, overexpression of SF2/ASF resulted in differential pX splice site utilization, whereas hnRNP A1 caused HTLV-1 exon 2 skipping (Princler et al., 2003). HTLV-1-infected cells and ATL cells have different profiles of cellular transcripts, as they accumulate alternatively spliced transcripts compared to uninfected cells. Such observations may denote lesions in the splicing machinery in HTLV-1-infected cells.

Translocation of cellular proteins into the nucleus is due to interaction between cis-acting NLSs in the protein and nuclear transport receptor complex (the importin complex). Usually, importin $\alpha$ serves as a bridge between the NLS and the import receptor importin $\beta$. It was demonstrated that the NLS of Rex directly bound to importin $\beta$ (Palmeri and Malim, 1999; Figure 2). The authors found that Rex was nuclear-imported by interactions with importin $\beta$ and independent of importin $\alpha$. Nucleolar phosphoprotein B-23, also known as nucleophosmin (NPM), is a phosphoprotein mainly localized in nucleoli. Previously, it was determined that B-23 bound to the $\mathrm{N}^{\prime}$-terminal NLS/NoLS of Rex (Adachi et al., 1993). As described above, the Rex-viral mRNA complex is transported to the cytoplasm by CRM1. The authors speculated that B-23 may assist the return of Rex to the nuclei/nucleoli, which is necessary for further export of unspliced viral mRNA from the nucleus by Rex (Adachi et al., 1993). Recently, interactions between Rex and Dicer were reported by Abe et al. (2010). Their experiments demonstrated that Rex directly interacted with Dicer and inhibited its function in processing short hairpin RNA (shRNA) to small interfering RNA (siRNA).

\section{IMPACT OF Rex ON THE HOST CELLULAR HOMEOSTASIS}

Viruses, including HTLV-1, utilize and direct host cellular mechanisms to facilitate viral replication through the whole life cycle. Such hijacking is achieved by direct interactions of viral and cellular proteins. The interactome and impacts of HTLV-1 Tax on the host cellular physiology have been well studied and described elsewhere, whereas those for Rex have not been thoroughly explored to date, even though numerous reports showed that Rex interacts with a wide variety of cellular proteins as mentioned above.

Rex up-regulates il-2r $\alpha$ mRNA expression, although the underlying mechanism has not been clarified. IL-2R $\alpha$ overexpression in HTLV-1-infected and ATL cells influences the response efficiency to IL-2. Rex is capable of stabilizing il-2ra mRNA up to fivefold (Kanamori et al., 1990, 1994); thus, the overexpression of this gene 
in HTLV-1-infected and ATL cells can be explained, at least partly, by the function of Rex. White et al. (1991) found that the NoLS of Rex (aa 1-19) was critical for stabilization of il-2ro mRNA. The molecular mechanism of il-2ro mRNA stabilization by Rex still needs to be elucidated. If Rex stabilizes general mRNA metabolism of the cell, including that of $i l-2 r \alpha$ mRNA, it is highly possible that Rex influences the expression levels of other cellular transcripts.

Fyn is a proto-oncogene that belongs to the membraneassociated tyrosine kinase family and has been implicated in malignant pathological processes, especially in melanoma progression, neuroblastoma genesis, and carcinoma invasion. Compared to its implications in carcinogenesis, the physiological significance of Fyn in hematological malignancy has not been investigated. Fyn protein has two major isoforms, Fyn-B and Fyn-T, which are derived from exon $7 \mathrm{~A}$ and $7 \mathrm{~B}$, respectively. Fyn-B is expressed in brain tissue, whereas Fyn-T is expressed exclusively in hematopoietic cells. Exon 7 of fyn encodes the linker region involved in intra-molecular interactions controlling Src tyrosine kinase regulation. Thus, the two isoforms have distinct functions in signal transduction and transforming capacity. Picard et al. (2004) reported that under pathological conditions, such as in acute lymphoblastic leukemia or chronic lymphocytic leukemia, expression of Fyn-B was significantly increased, as confirmed in cell lines and fresh patient cells. The author also mentioned that $f y n-b$ mRNA levels are significantly increased in the HTLV-1-infected cell line, C91. Indeed, several years earlier, Weil et al. (1999) found for the first time that fyn-b mRNA is up-regulated in C91 cells and Rex is responsible for the down-regulation of alternative exon usage. Thus, abnormal exon selection of $f y n$ mRNA is widely observed in various hematopoietic malignancies; however, the viral Rex protein may induce dysregulation in the host splicing machinery in HTLV-1-infected cells. The detailed molecular events explaining the implication of Rex in alternative splicing of Fyn and the physiological impacts of Fyn-B overexpression in T-cells have not been investigated. However, since Rex is an RNA binding protein, which has been implicated in the splicing machinery by several researchers, it is possible that Rex has the capacity to influence the splicing preference, resulting in an altered expression ratio of Fyn-B and Fyn-T in infected T-cells.

\section{SIMILARITIES AND DIFFERENCES BETWEEN HTLV-1 Rex AND HTLV-2 Rex}

HTLV-1 and HTLV-2 belong to the same genus (Vandamme et al., 1998) and share a high homology in genomic structure (Figure 3). Both are able to infect human T-cells and induce immortality. In spite of a high similarity in the genome and life cycle, there is a significant difference in pathogenesis between retroviruses. The most outstanding difference is that HTLV-1 induces a severe hematopoietic malignancy (ATL), whereas HTLV-2 does not (Figure 3). It is unclear as to why there is such a significant difference in outcomes from similar genomic structures. Nevertheless, current knowledge indicates that the differences in properties and functions of accessory and regulatory proteins expressed from the $\mathrm{pX}$ region of the virus are critical for the distinct pathological differences between the HTLVs.

Both HTLV-1 and HTLV-2 encode Tax and Rex, the major transcriptional and post-transcriptional regulators. Tax-1 from

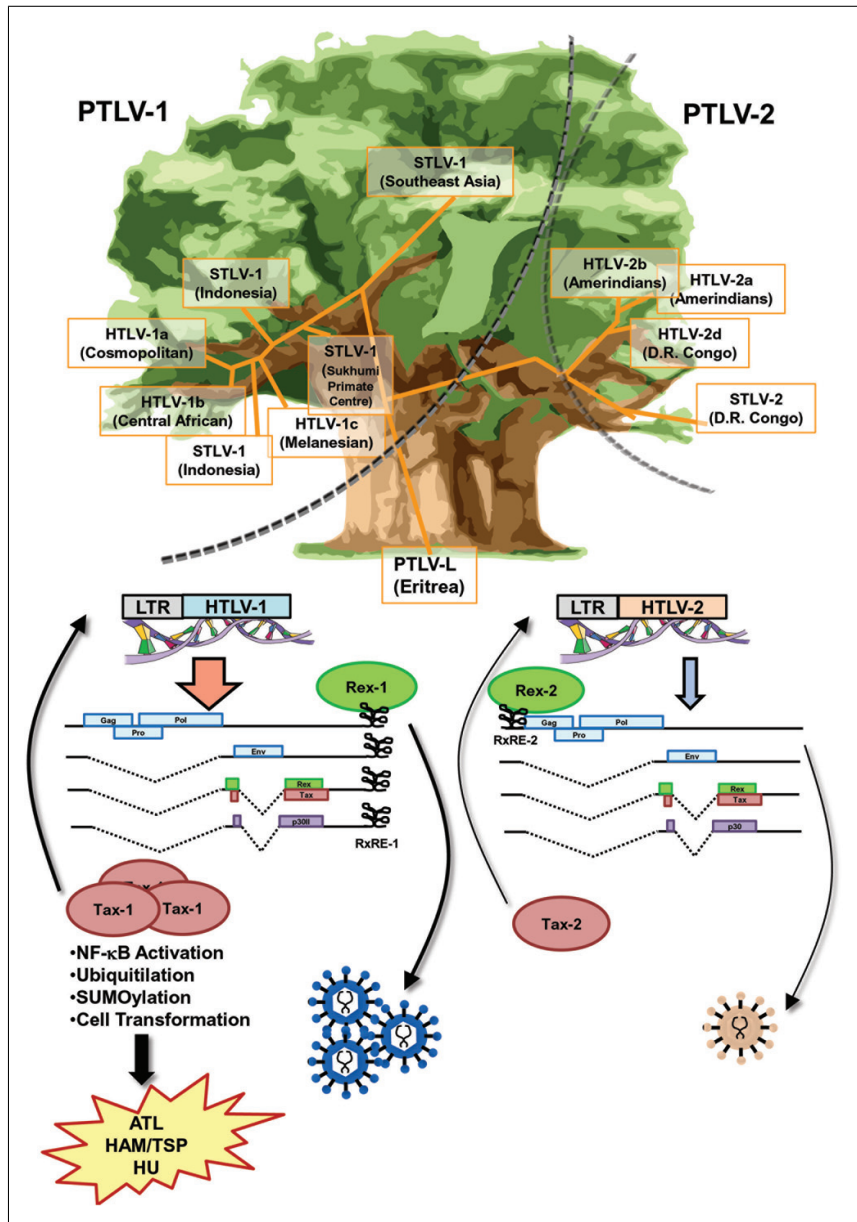

FIGURE 3 | Similarities and differences between Rex-1 and Rex-2. The phylogenetic tree of HTLV, which is drawn based on the report by Vandamme et al. (1998), shows that the major branches of PTLV-1 and PTLV-2 separated at an early stage. Sub-branches of STVL-1 and HTLV-1 or STLV-2 and HTLV-2 were separated within each major branch thereafter. Yet, the genomic structures of HTLV-1 and HTLV-2 are very similar and both viruses encode Tax and Rex, the major transcriptional and post-transcriptional regulators, respectively. Both Tax-1 and Tax-2 have NLS, NES, and ATF/CREB binding domains, whereas only Tax-1 has a distinct NF- $\mathrm{KB}$ activating domain and p300 binding domain, as well as a number of PTM sites, for phosphorylation, ubiquitination, and SUMOylation, resulting in stronger transactivation and transforming activities than those of Tax-2. Both Rex-1 and Rex-2 are phosphoproteins sharing 60\% similarity with overlapped major functional domains, such as NLS, NES, and SD at the 3 '-terminus. The RxRE motif of HTLV-1 mRNA (RxRE-1) is located in the U3/R region and all HTLV-1 mRNA have intact RxRE-1s in the $3^{\prime} U T R s$. On the other hand, the RxRE of HTLV-2 (RxRE-2) is located at the R/U5 region and only unspliced mRNA maintains the intact RxRE-2. Thus, Rex-1 is capable of transporting all viral mRNA including tax/rex mRNA and enhancing the expression of Tax for further transactivation of LTR, whereas Rex-2 is not. Overall, Rex-1 may have a stronger impact on viral replication through the enhancement of Tax-1 expression compared with Rex-2. Different roles of Tax and Rex may be related to the differences in pathophysiologies of HTLV-1 and HTLV-2.

HTLV-1 shows transforming ability, whereas Tax-2 from HTLV-2 does not. Thus, the different transforming activity of Tax determines the malignant pathology of this virus (Feuer and Green, 2005). Both Tax-1 and Tax-2 consist of NLS, NES, and ATF/CREB binding domains. On the other hand, only Tax-1 has a distinct 
NF- $\kappa \mathrm{B}$ activating domain and p300 binding domain, as well as a number of post-translational modification (PTM) sites, such as phosphorylation, ubiquitination, and small ubiquitin-like modifier (SUMO)ylation (Rende et al., 2012). Generally, Tax-1 has stronger transactivation and transforming activities than Tax-2 (Figure 3).

Rex- 1 encoded in HTLV-1 is a $27-\mathrm{kDa}$ (189 aa) protein, whereas Rex-2 from HTLV-2 consists of 170 aa and its molecular weight ranges between 24 and $26 \mathrm{kDa}$ depending on the phosphorylation-induced conformational changes (Kesic et al., 2009b; Xie etal., 2009). Rex-1 and Rex-2 share 60\% similarity with overlapped major functional domains, such as RNA binding domain (RBD)/NLS at the N-terminus region, two multimerization domains, activity domain (AD)/NES, and SD at the 3 '-terminus. In Rex-2, the inhibitory domain (ID) is overlapping with SD. Both Rex proteins are phosphoproteins and their activities are regulated by their phosphorylation status. Furthermore, Rex-1 and Rex-2 have isoforms derived from alternative splicing. p21Rex is the $\mathrm{N}^{\prime}$-truncated form of p27Rex, which lacks 78 aa of the N-terminus region, including RBD/NLS and the $\mathrm{N}^{\prime}$-multimerization domain (Kiyokawa et al., 1985). Alternative splicing inclusion of exon 2 yields p27Rex, whereas exon 2 skipping yields p21Rex (Orita et al., 1993). Since p21Rex does not have a NLS, it localizes to the cytoplasm. However, the functional importance of this isoform has not yet been elucidated. p21Rex transcripts are constitutively expressed in HTLV-1-infected cell lines and in primary peripheral blood mononuclear cells from HTLV-1 carriers and ATL patients (Berneman et al., 1992; Orita et al., 1992; Saiga etal., 1996). Thus, it is expected that p21Rex plays a role in the HTLV-1 life cycle, probably as a dominant negative form of p27Rex. Exon 2 skipping in HTLV-2 also yields $\mathrm{N}^{\prime}$-terminus-truncated forms of Rex-2 (tRex). Translation from the first AUG codon located within the $\mathrm{x}$-III ORF results in two major protein isoforms of 22 and $20 \mathrm{kDa}$, as well as a minor protein isoform of $18-\mathrm{kDa}$ depending on PTMs, whereas translation from the second AUG of the $\mathrm{x}$-III ORF produces a $17-\mathrm{kDa}$ protein (Rende et al., 2012). Ciminale et al. (1997) reported that tRex inhibited the function of the wild type Rex-2 by influencing the phosphorylation status and consequently, the subcellular localization of Rex-2.

A major difference between HTLV-1 and HTLV-2 regarding Rex function may be the position of RxRE in the viral transcripts (Figure 3). The RxRE motif of HTLV-1 mRNA (RxRE-1) is located in the U3/R region; consequently, all HTLV-1 mRNA have an intact RxRE-1 in the $3^{\prime} \mathrm{UTR}$. On the other hand, the RxRE of HTLV-2 (RxRE-2) is located in the R/U5 region and only unspliced mRNA maintains an intact RxRE-2 (Rende et al., 2012). The principal function of Rex is selective nuclear export of unspliced or partially spliced viral mRNA. Recently, Bai et al. (2012) demonstrated that the nuclear export of the doubly spliced tax/rex mRNA of HTLV-1 was also enhanced by Rex-1 in a RxRE-1/CRM1-dependent manner. Considering the position of RxRE in the two HTLVs, Rex-1 may be capable of transporting all viral mRNA including tax/rex mRNA and enhancing Tax expression for further transactivation of LTR, whereas Rex2 is not. Although Rex-1 and Rex-2 have similar capacities as RNA binding proteins, Rex-1 may have a stronger impact on viral replication through the enhancement of Tax expression (Figure 3).

The stability and efficiency of nuclear export of viral mRNA are determined by two cis-acting elements, RxRE and CRS, which function in a competing fashion. CRS is a nuclear retention signal that induces destabilization and inefficient nuclear-export of viral mRNA, although other proteins binding to CRS, either viral or cellular, have not yet been identified. The CRS is localized in the 5'LTR of HTLV-1 (Seiki et al., 1990) and HTLV-2 (Black et al., 1991). In both HTLVs, the 5'LTR CRS spans from the R region to the U5 region; thus, only unspliced viral mRNA contains intact CRS in either virus. HTLV-1 contains a second CRS at the 3'LTR overlap with RxRE-1 (King et al., 1998) resulting in all HTLV-1 mRNA containing intact RxRE-1 and CRS in the $3^{\prime}$ LTR. The CRS overlaps with RxRE in both HTLV-1 and HTLV-2; therefore, it is possible that binding of Rex to RxRE might modulate the fate of viral mRNA (i.e., nuclear retention by CRS or nuclear export by Rex). Overall, it seems that Rex-1 might influence viral mRNA trafficking in a broader range compared with Rex2 which targets only the unspliced $h t l v-2$ mRNA in terms of RxRE and CRS.

\section{SIMILARITIES AND DIFFERENCES BETWEEN HTLV-1 Rex AND HIV-1 Rev}

HTLV-1 and HIV-1 are evolutionally distinct, but both belong to a family of complex retroviruses sharing tropism for human CD4 ${ }^{+}$ T-cells. Although they have similar genetic structures and encode homologous viral proteins, the overall life cycle, controlled by viral accessory and regulatory proteins, are clearly different. This results in different disease associations [i.e., ATL by HTLV-1 and acquired immune deficiency syndrome (AIDS) by HIV-1]. Both viruses encode transactivators, HTLV-1 Tax and HIV-1 Tat, and posttranscriptional regulators, HTLV-1 Rex and HIV-1 Rev. Although Tax and Tat transactivate their respective LTRs, they act though different mechanisms and cannot be replaced by each other. On the other hand, even though the homology in the sequence of HTLV-1 Rex and HIV-1 Rev is low, they play similar functions through common cellular pathways (Baydoun et al., 2008; Suhasini and Reddy, 2009). A major similarity is that both Rex and Rev are RNA binding proteins and specifically bind to respective viral mRNA with high affinity through RxRE for Rex and the Rev responsive element (RRE) for Rev (Figure 4). Both Rex and Rev have argininerich sequences that are necessary for binding to their respective responsive elements. They stabilize unspliced or partially spliced viral mRNA and actively transport them to the cytoplasm for selective translation of viral structural proteins. The functional similarities and differences between HTLV-1 Rex and HIV-1 Rev were extensively investigated from late 1980s to the early 1990s.

Rimsky et al. (1988) first reported that the function of HIV-1 Rev could be replaced by that of HTLV-1 Rex. Rev induces translation of shorter forms of the Tat protein from the unspliced form of tat mRNA using a stop codon within the intron of tat mRNA, meaning that Rev suppresses splicing and stabilizes unspliced tat mRNA (Malim et al., 1988). Rimsky et al. (1988) also demonstrated that HTLV-1 Rex overexpression resulted in the stabilization of unspliced tat mRNA and enhanced translation of the truncated Tat protein. They also demonstrated that depressed 


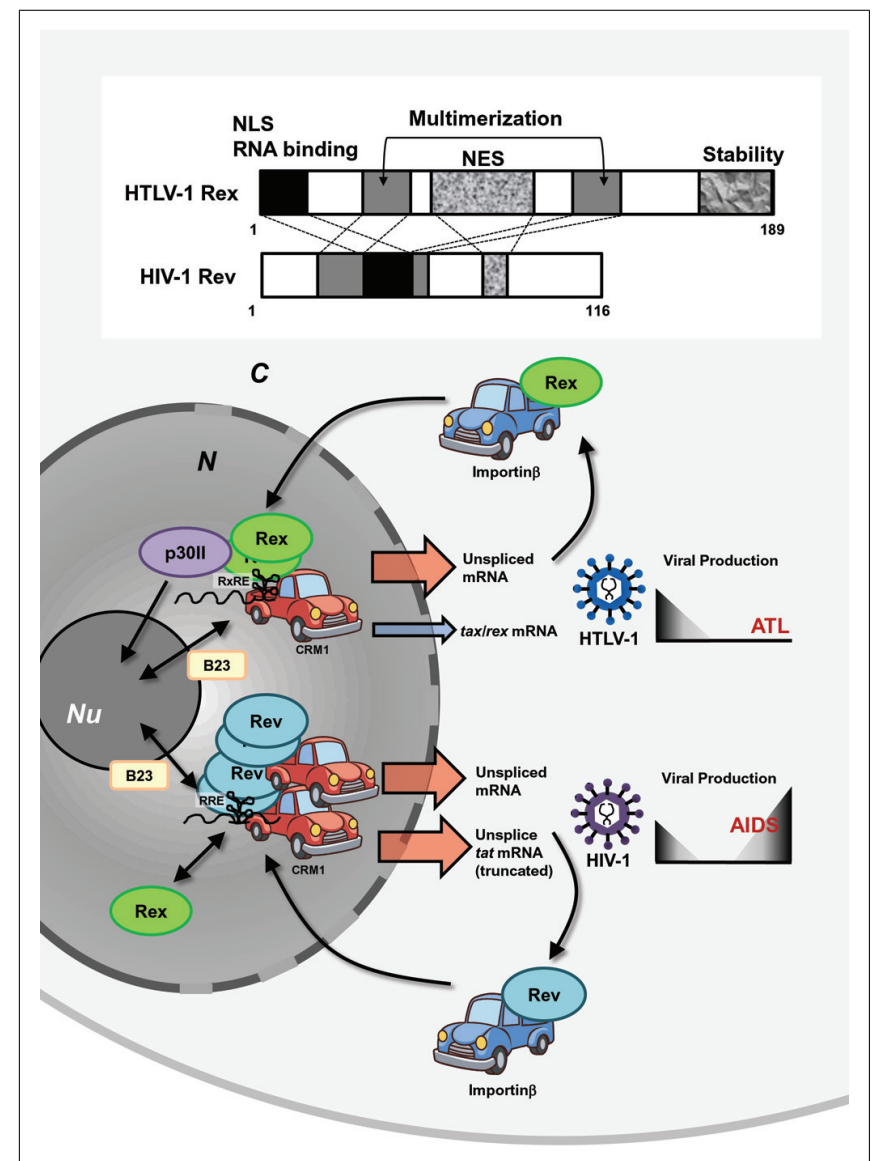

FIGURE 4 | Similarities and differences between HTLV-1 Rex and HIV-1 Rev. HTLV-1 and HIV-1 are evolutionally distinct, but both belong to a family of complex retroviruses. Both viruses encode transactivators, HTLV-1 Tax and HIV-1 Tat, and post-transcriptional regulators, HTLV-1 Rex and HIV-1 Rev. Although Tax and Tat transactivate their respective LTRs, they act though different mechanisms and cannot be replaced with each other. On the other hand, even though the homology in the primary sequence of HTLV-1 Rex and HIV-1 Rev is low, they carry out similar functions through common domains, such as NES, NLS, and multimerization domains. They are RNA binding proteins and specifically bind to respective viral mRNA with high affinity through RxRE for Rex and RRE for Rev. They stabilize unspliced or partially spliced viral mRNA and actively transport them to the cytoplasm via CRM1 binding for selective translation of viral structural proteins and return to the nucleus by interactions with Importin $\beta$. Rex can function through RRE, while Rev cannot bind to RxRE. HTLV-1 Tax is translated only from fully spliced viral mRNA; thus, stabilization and active nuclear transport of unspliced HTLV-1 mRNA by Rex reduces the relative expression rate of Tax. On the contrary, HIV-1 Rev does not suppress Tat activity, since it enhances truncated, yet active, Tat proteins. Thus, it is expected that HTLV-1 Rex favors reduction of viral production, whereas HIV-1 Rev may support active viral production. N, nucleus; C, cytoplasm; $\mathrm{Nu}$, nucleolus.

viral production from $H I V-1-\Delta$ Rev was rescued by co-transfection with HTLV-1 Rex-expressing plasmids. The authors emphasized the importance of the cellular post-transcriptional pathways for viral expression, which is shared by structurally distinct HIV-1 Rev and HTLV-1 Rex. Later, it was found that Rex functions through RRE (Hanly et al., 1989); however, Rex and Rev target different sequences within RRE (Solomin et al., 1990). Interestingly, although Rex can function through RRE, Rev cannot bind to
RxRE (Hanly et al., 1989). Nevertheless, HTLV-1 Rex and HIV-1 Rev function through a similar mechanism for stabilization and active nuclear export of unspliced mRNA and the distinct genomic structures of these retroviruses furnish Rex and Rev with different expression levels of the transactivators Tax and Tat, respectively. Since Tax is translated only from fully spliced viral mRNA, stabilization and active nuclear transport of unspliced HTLV-1 mRNA by Rex eventually reduces the relative expression rate of Tax (Hidaka et al., 1988); thus, Rex might play an important role in the establishment of viral latency. On the other hand, HIV-1 Rev does not suppress Tat activity but enhances a truncated, yet active, Tat protein, as described above (Malim et al., 1988). Thus, the overall biological function of these viral post-transcriptional regulators in the viral life cycle may not be totally overlapped (Figure 4).

The arrangements of primary Rex and Rev structures are distinctive; however, both viral RNA binding proteins have NLSs and NESs and also use the same cellular nucleocytoplasmic shuttling machinery (Pollard and Malim, 1998; Kesic et al., 2009a; Figure 4). After translation, the NLSs of both Rex and Rev bind to importin $\beta$ and the complexes are then translocated to the nucleus (Palmeri and Malim, 1999; Truant and Cullen, 1999; Yoneda, 2000). Another key player of Rex/Rev nuclear import is B-23, a nucleolar phosphoprotein, and probably because of binding to B-23, these viral proteins localize strongly to the nucleoli. In the nucleolus, Rex and Rev bind to RxRE- and RRE-containing viral mRNA, respectively, and the viral RNA complex is exported to the cytoplasm for translation by CRM1 binding through NESs of Rex or Rev. Monomeric Rev has the highest affinity to RRE, but additional binding of up to $12 \mathrm{Rev}$ molecules is required for effective nuclear export by CRM1 (Zapp et al., 1991; Zemmel et al., 1996). On the other hand, although monomeric Rex retains its ability to shuttle between the cytoplasm and nucleus, multimerization is essential for the function of Rex in stabilization and transport of viral unspliced RNA and CRM1 is involved in the multimerization process of Rex (Hakata et al., 1998, 2001; Baydoun et al., 2008). p30II, a negative post-transcriptional regulator of HTLV-1 (Nicot et al., 2004), has multiple NoLSs, and retains tax/rex mRNA as well as Rex proteins in the nucleoli. Therefore, p30II is considered to suppress HTLV-1 expression (Ghorbel et al., 2006; Sinha-Datta et al., 2007). There is no counterpart of p30II in HIV-1. Thus, it can be speculated that Rev alone has a NoLS strong enough to retain itself in nucleoli and multimerization is necessary for interacting with multiple CRM1s to be exported from the nucleolus. On the other hand, Rex may have less powerful NoLSs and without p30II, monomeric Rex can be exported by CRM1, although multimerization is necessary for this protein to interact with RxRE-containing viral RNA (Figure 4).

Involvement of both Rex and Rev in the cellular splicing machinery is expected, since both protect unspliced viral RNA. HIV-1 Rev strongly interacts with the splicing co-factor p32 (Tange et al., 1996). The p32 protein is one of three polypeptides composing active SF2/ASF in HeLa cells, which are involved in many splicing events and are required for splice site selection in a concentration-dependent manner (Krainer et al., 1991). Later, SF2/ASF was also shown to bind to RRE in a Rev-dependent manner (Powell et al., 1997). Therefore, p32 may function as a bridge between Rev and SF2/ASF to recruit an optimal amount 
of SF2/ASF to RRE in order to inhibit splicing of HIV-1 mRNA, although the molecular mechanism of Rev in inhibition of splicing has not been fully clarified.

HTLV-1 Rex is also known to inhibit the early phase of splicing (Younis and Green, 2005) through interactions with SF2/ASF, although the pathways have not been extensively examined compared with HIV-1 Rev. hnRNA binding proteins (hnRNPs) associated with pre-mRNA in the nucleus influence pre-mRNA processing/splicing and transport of mature mRNA. hnRNP A1 was demonstrated to bind to RxRE in a competing manner to Rex (Duc Dodon etal., 2002) and inhibit the function of Rex (Kress etal., 2005). The authors found that the basal level of hnRNP A1 was lower in HTLV-1-producing cell lines (C91PL, MT2, and HUT102) compared with non-HTLV-1-infected T-cell lines (CBL and Jurkat), proposing that HTLV-1 may have evolved a mechanism to down-regulate hnRNP A1 because it is not beneficial to viral replication. Several reports indicated that Rex was involved in post-transcriptional regulation of the host genome. For example, Rex stabilizes il-2ra mRNA, with its NLS playing an important role (Kanamori et al., 1990; White et al., 1991). Further, Rex enhances the alternative usage of exon 7 in fyn mRNA to yield the brain-type Fyn-B, instead of T-cell-type Fyn-T (Weil et al., 1999). The underlying mechanism by which Rex influences cellular post-transcriptional regulation has not yet been fully clarified. It is possible that Rex interacts with cellular splicing factors to enhance viral replication, which may cause incidental alterations in host transcriptional homeostasis.

Although HTLV-1 Rex and HIV-1 Rev are structurally distinct, they have evolved a similar function, i.e., inhibition of splicing and stabilization and nuclear-export of unspliced viral mRNA through interactions with common cellular factors. On the other hand, the difference between these two post-transcriptional regulators might be reflected in the different pathophysiological characteristics of HTLV-1 and HIV-1.

\section{NEW TOPICS IN HTLV-1 Rex MOLECULAR BIOLOGY FROM RECENT STUDIES}

Cellular physiological pathways are achieved by functional combinations of cellular proteins. It has been clarified that such protein-protein interactions are achieved through short linear motifs (SLiMs) consisting of 3-13 aa, rather than large structural domains of each protein (Davey et al., 2012). Interestingly, SLiMs were first identified in viruses and it was discovered later that the viruses actually mimic the functional motifs of cellular proteins to hijack the cellular pathways (Kadaveru etal., 2009; Davey etal., 2011). SLiMs participate in all aspects of cellular biology, such as protein-protein binding ( $\mathrm{SH} 3$ domain interactions), targeting (NLS and NES), PTMs (phosphorylation, SUMOylation, and ubiquitination), and cleavage, which also overlap with the viral life cycle from entry to budding in the host cells. However, viral mimicry of host SLiMs has not been fully investigated. Davey et al. (2011) reviewed 52 viral mimicry instances among approximately 150 reported eukaryotic motifs in human papillomavirus (HPV), Epstein-Barr virus (EBV), human T-cell lymphotropic virus (HTLV), adenovirus, human immunodeficiency virus (HIV), and influenza virus. Nevertheless, the authors were expecting more extended mimicry by viruses. The

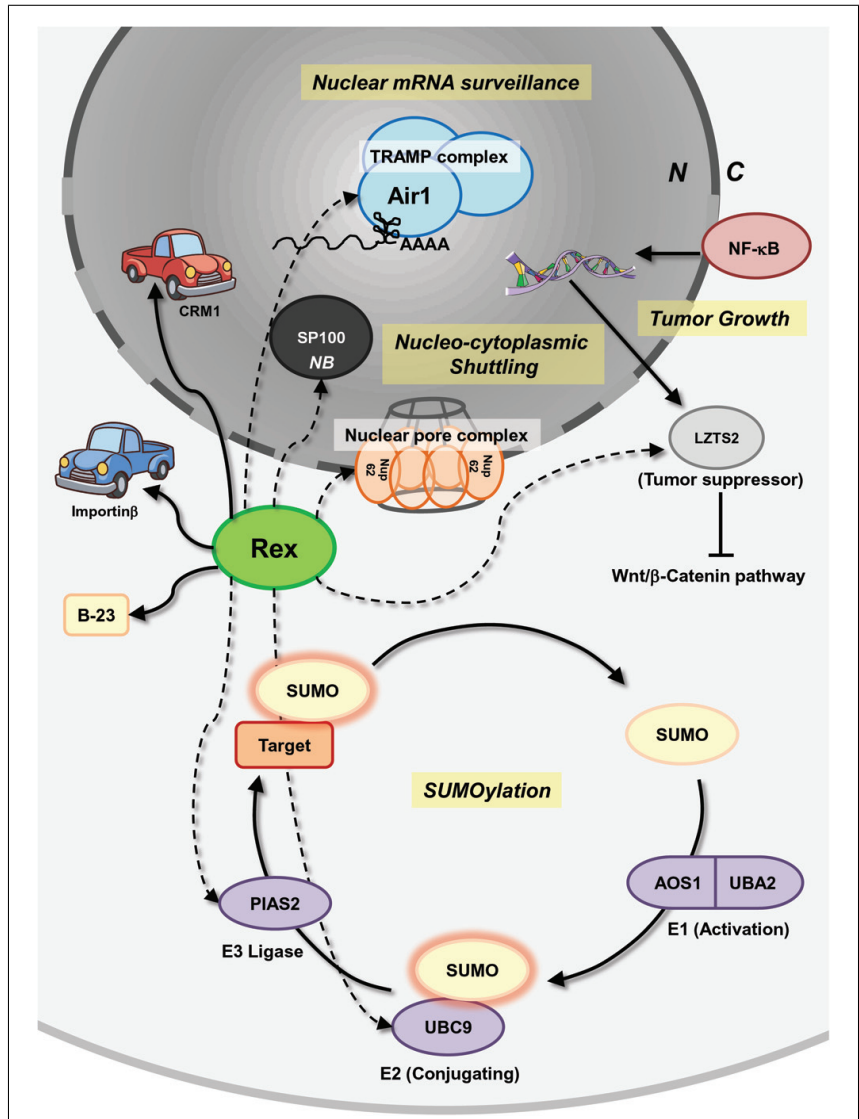

FIGURE 5 | Interactions of Rex with host pathways, uncovered and covered. Besides the known interactions between Rex and CRM-1, importin $\beta$, and B-23, a number of potential interactions between Rex and cellular proteins, based on the high-throughput yeast two-hybrid system, were reported by Simonis et al. (2012). Rex is suspected of interacting with a series of proteins that play crucial roles in mRNA surveillance, nucleocytoplasmic shuttling, tumor growth regulation, and SUMOylation. Air1 (ZCCHC7) is a component of the TRAMP complex, which is involved in nuclear mRNA surveillance. NUP62 is one of three nucleoporins (NUP54,

58 , and 62) composing the nuclear pore complex and is essential for nuclear transport. LZTS2 is a tumor suppressor and its expression is transcriptionally regulated by NF-kB. LZTS2 expression levels affect cell proliferation and tumor growth through the Wnt/ $\beta$-catenin pathway in various cancer cell lines. An E2 SUMO ligase, UBC9, and an E3 SUMO ligase, PIAS2, are also expected to interact with Rex. Rex is also expected to interact with SP100, a major component of the nuclear body, which has a transactivating function and is induced in stimulated and malignant cells. Since Rex impacts the host cell through an unknown mechanism, such as increasing il-2ra mRNA level and fyn-b mRNA expression level by enhancing unusual exon 7 usage, unknown interactions between Rex and cellular proteins may be related to Rex functions. Solid lines indicate reported interactions. Dashed lines indicate potential interactions. N, nucleus; C, cytoplasm; NB, nuclear body.

well-known viral mimicry of HTLV-1 Rex involves NLS and NES in cellular nucleocytoplasmic shuttling. Since this viral posttranscriptional regulator extensively functions by means of host cellular pathways in various steps of the HTLV-1 life cycle, Rex may have other mimicry motifs that have not yet been discovered.

Recently, comprehensive interactomes, based on the highthroughput yeast two-hybrid system (Rual et al., 2005; Venkatesan etal., 2009), between HTLV-1/HTLV-2 viral proteins and 
human proteins were reported by Simonis etal. (2012). The authors discovered (including confirmation of previous reports) 87 and 79 interactions between HTLV-1- and HTLV-2-encoded proteins, respectively, and 122 human proteins participated in Ub-proteasome pathways, apoptosis, oncogenesis, and Notch signaling. For HTLV-1 Rex, 18 novel interactions were identified, including an interaction with Dic2 (Rho-Gap protein) and BHLHB2 (a transcription repressor) having an anti-apoptotic function. Recently, it was demonstrated that BHLHB2 mediated HIF- $1 \alpha$-induced microphthalmia-associated transcription factor (MITF) suppression, which causes increased metastasis in melanoma cells (Cheli et al., 2011). In addition, Rex is suspected of interacting with a series of proteins that play crucial roles in mRNA surveillance, nucleocytoplasmic shuttling, tumor growth regulation, and SUMOylation (Figure 5). The cellular proteins listed below potentially interact with Rex. Air1 (ZCCHC7) is a component of the Trf4/Air2/Mtr4 polyadenylation (TRAMP) complex, which is involved in nuclear mRNA surveillance (Fasken et al., 2011). NUP62 is one of three nucleoporins (NUP54, 58, and 62) composing of the nuclear pore complexes that are essential for nuclear transport (Solmaz et al., 2011). The interaction between viral proteins and NUP62 has been reported in HIV-1, herpes simplex virus, and EBV. In HIV-1, it is speculated that Rev reorganizes the architecture of nuclear pore complexes, including NUP62, for efficient viral RNA transport (Monette et al., 2011). In addition, HIV-1 integrase interacts with NUP62 on chromatin for integration of the viral genome (Ao et al., 2012). The HCV posttranscriptional regulator ICP27 was demonstrated to directly bind NUP62 to inhibit cellular trafficking and increase viral mRNA transport (Malik et al., 2012). Finally, EBV BGLA4, a viral serine/threonine kinase, was shown to interact with NUP62 and NUP153 and translocate itself to the nucleus even though this protein does not have any clear NLSs (Chang et al., 2012). LZTS2, a tumor suppressor, which is transcriptionally regulated by NF- $\kappa$, and the modulation of LZTS2 expression affects cell proliferation and tumor growth through the $\mathrm{Wnt} / \beta$-catenin pathway in various

\section{REFERENCES}

Abe, M., Suzuki, H., Nishitsuji, H., Shida, H., and Takaku, H. (2010). Interaction of human T-cell lymphotropic virus type I Rex protein with Dicer suppresses RNAi silencing. FEBS Lett. 584, 4313-4318.

Adachi, Y., Copeland, T. D., Hatanakall, M., and Oroszlansii, S. (1993). Nucleolar targeting signal of Rex protein of human T-cell leukemia virus type I specifically binds to nucleolar shuttle protein B-23. J. Biol. Chem. 268, 13930-13934.

Adachi, Y., Copeland, T. D., Takahashi, C., Nosaka, T., Ahmed, A., Oroszlan, S., and Hatanaka, M. (1992). Phosphorylation of the Rex protein of human T-cell leukemia virus type I. J. Biol. Chem. 267, 2197721981.

Adachi, Y., Nosaki, T., and Hatanaka, M. (1990). Protein kinase inhibitor H-7 blocks accumulation of unspliced
mRNA of human T-cell leukemia virus type I (HTLV-I). Biochem. Biophys. Res. Commun. 169, 469-475.

Ahmed, Y. F., Gilmartin, G. M., Hanly, S. M., Nevins, J. R., and Greene, W. C. (1991). The HTLV-I Rex response element mediates a novel form of mRNA polyadenylation. Cell 64 727-737.

Ahmed, Y. F., Hanly, S. M., Malim, M. H., Cullen, B. R., and Greene, W. C. (1990). Structure-function analyses of the HTLV-I Rex and HIV-1 Rev RNA response elements: insights into the mechanism of Rex and Rev action. Genes Dev. 4, 1014-1022.

Andresen, V. Pise-Masison, C. A., SinhaDatta, U., Bellon, M., Valeri, V., Parks, R. W., Cecchinato, V., Fukumoto, R., Nicot, C., and Franchini, G. (2011). Suppression of HTLV-1 replication by Tax-mediated rerouting of the p13 viral protein to nuclear speckles. Blood 118, 1549-1559.

cancer cell lines (Kim et al., 2011). An E2 SUMO ligase, UBC9, and an E3 SUMO ligase, PIAS2, are also expected to interact with Rex. SUMOylation is a major PTMs (Seeler and Dejean, 2001; Gareau and Lima, 2010), which modulates the function of a large number of proteins, but its dysfunction is closely related to pathogenesis (Wimmer et al., 2012). Rex also reportedly interacts with SP100, a major component of a nuclear body (NB), which has a transactivating function and is induced in stimulated and malignant cells. The function of SP100 in modification of molecular dynamics of a NB is regulated by SUMOylation (Riley et al., 2005; Bossis and Melchior, 2006). As shown in Figure 5, there is a wide variety of cellular proteins that potentially interact with Rex. Taken as a whole, HTLV-1 Rex has a great potential to be involved in or even direct unknown cellular pathways.

\section{CONCLUSION}

HTLV-1 Rex is a major post-transcriptional regulator of viral expression, which is responsible for active viral replication in the early phase of infection and for reduction of viral activity to establish latency in the late phase of infection. The molecular biology of Rex was extensively investigated for a decade from the 1980s to the early 1990s; however, once the molecular mechanisms of nuclear export of unspliced viral mRNA by Rex was clarified, the major interest was shifted to the function of Tax to understand HTLV-1 virology and pathology. Nevertheless, our understanding of various aspects of HTLV-1 Rex inside and outside of the viral life cycle is incomplete. For example, it is unclear how Rex inhibits splicing of viral mRNA (and probably the host mRNA), and the extent of the influence of Rex by making use of the cellular pathways for viral benefits. We still do not know the underlying mechanism by which Rex increases il-2ro mRNA or the impacts on the host cell caused by unusual exon-usage for production of Fyn-B. Several reports already proposed the possibility of unknown biology of HTLV-1 Rex. Detailed and extended investigations based on uncovered facts and recent knowledge may open new pathways to discover hidden aspects of HTLV-1 Rex.

Anupam, R., Datta, A., Kesic, M., Green-Church, K., Shkriabai, N., Kvaratskhelia, M., and Lairmore, M. D. (2011). Human T-lymphotropic virus type 1 p30 interacts with REGgamma and modulates ATM (ataxia telangiectasia mutated) to promote cell survival. J. Biol. Chem. 286, 76617668.

Ao, Z., Jayappa, K. D., Wang, B., Zheng, Y., Wang, X., Peng, J., and Yao, X. (2012). Contribution of host nucleoporin 62 in HIV-1 integrase chromatin association and viral DNA integration. J. Biol. Chem. 287, 10544-10555.

Arnold, J., Yamamoto, B., Li, M., Phipps, A. J., Younis, I., Lairmore, M. D., and Green, P. L. (2006). Enhancement of infectivity and persistence in vivo by $\mathrm{HBZ}$, a natural antisense coded protein of HTLV-1. Blood 107, 3976-3982.
Awasthi, S., Sharma, A., Wong, K., Matlock, E. F., Rogers, L., Takemoto, S., Taguchi, H., Michael, D., Lüscher, B., Dittrich, O., Tagami, H., Nakatani, Y., Mcgee, M., Girard, A., Gaughan, L., Robson, C. N., Monnat, R. J. Jr., Harrod, R., Zhang, J., Motloch, P., Cole, M. D., and Monnat, R. J. (2005). A human t-cell lymphotropic virus type 1 enhancer of myc transforming potential stabilizes Myc-TIP60 transcriptional interactions. Mol. Cell. Biol. 25, 6178-6198.

Bai, X. T., Baydoun, H. H., and Nicot, C. (2010). HTLV-I p30: a versatile protein modulating virus replication and pathogenesis. Mol. Aspects Med. 31, 344-349.

Bai, X. T., Sinha-Datta, U., Ko, N. L., Bellon, M., and Nicot, C. (2012). Nuclear export and expression of HTLV-I tax/rex mRNA is RxRE/Rex-dependent. J. Virol. 86, 4559-4565. 
Balvay, L., Lastra, M. L., Sargueil, B., Darlix, J., and Ohlmann, T. (2007). Translational control of retroviruses. Nat. Rev. 5, 128-140.

Baydoun, H. H., Bellon, M., and Nicot, C. (2008). HTLV-1 Yin and Yang: Rex and p30 master regulators of viral mRNA trafficking. AIDS Rev. 10 , 195-204.

Baydoun, H. H., Pancewicz, J., and Nicot, C. (2011). Human T-lymphotropic type 1 virus p30 inhibits homologous recombination and favors unfaithful DNA repair. Blood 117, 5897-5906.

Berneman, Z. N., Gartenhaus, R. B., Reitz, M. S., Blattner, W. A., Manns, A., Hanchard, B., Ikehara, O., Gallo, R. C., and Klotman, M. E. (1992). Expression of alternatively spliced human T-lymphotropic virus type I pX mRNA in infected cell lines and in primary uncultured cells from patients with adult T-cell leukemia/lymphoma and healthy carriers. Proc. Natl. Acad. Sci. U.S.A. 89, 3005-3009.

Biasiotto, R., Aguiari, P., Rizzuto, R., Pinton, P., D'Agostino, D. M., and Ciminale, V. (2010). The p13 protein of human $\mathrm{T}$ cell leukemia virus type 1 (HTLV-1) modulates mitochondrial membrane potential and calcium uptake. Biochim. Biophys. Acta 1797, 945-951.

Black, A. C., Chen, I. S. Y., Arrigo, S., Ruland, C. T., Allogiamento, T., Chin, E. V. A., and Rosenblalt, J. D. (1991). Regulation of HTLV-II gene expression by Rex involves positive and negative cis-acting elements in the $5^{\prime}$ long terminal repeat. Virology $181,433-444$.

Bossis, G., and Melchior, F. (2006). SUMO: regulating the regulator. Cell Div. 1, 13.

Boxus, M., Twizere, J., Legros, S. Dewulf, J., Kettmann, R., and Willems, L. (2008). The HTLV-1 Tax interactome. Retrovirology 5, 76.

Chang, C. W., Lee, C. P., Huang, Y. H., Yang, P. W., Wang, J. T., and Chen, M. R. (2012). Epstein-Barr Virus protein kinase BGLF4 targets the nucleus through interaction with nucleoporins. J. Virol. 86, 80728085.

Cheli, Y., Giuliano, S., Fenouille, N., Allegra, M., Hofman, V., Hofman, P., Bahadoran, P., Lacour, J.P., Bertolotto, C., and Ballotti, R. (2011). Hypoxia and MITF control metastatic behaviour in mouse and human melanoma cells. Oncogene 31, 2461-2470.

Choudhary, G., and Ratner, L. (2011). The HTLV-1 hbz antisense gene indirectly promotes tax expression via down-regulation of p30(II) mRNA. Virology 410, 307-315.

Ciminale, V., Zotti, L., D’Agostino, D. M., and Chieco-Bianchi, L. (1997). Inhibition of human T-cell leukemia virus type 2 Rex function by truncated forms of Rex encoded in alternatively spliced mRNAs. J. Virol. 71, 2810-2818.

Corradin, A., Di Camillo, B., Rende, F., Ciminale, V., Toffolo, G. M., and Cobelli, C. (2010). Retrovirus HTLV-1 gene circuit: a potential oscillator for eukaryotes. Pac. Symp. Biocomput. 432, 421-432.

Davey, N. E., Travé, G., and Gibson, T. J. (2011). How viruses hijack cell regulation. Trends Biochem. Sci. 36, 159-169.

Davey, N. E., Van Roey, K., Weatheritt, R. J., Toedt, G., Uyar, B., Altenberg, B., Budd, A., Diella, F., Dinkel, H., and Gibson, T. J. (2012). Attributes of short linear motifs. Mol. Biosyst. 8 268-281.

Duc Dodon, M., Hamaia, S., Martin, J., and Gazzolo, L. (2002). Heterogeneous nuclear ribonucleoprotein $\mathrm{Al}$ interferes with the binding of the human $\mathrm{T}$ cell leukemia virus type 1 Rex regulatory protein to its response element. J. Biol. Chem. 277, 18744 18752

Fasken, M. B., Leung, S. W., Banerjee, A., Kodani, M. O., Chavez, R., Bowman, E. A., Purohit, M. K., Rubinson, M. E., Rubinson, E. H., and Corbett, A. H. (2011). Airl zinc knuckles 4 and 5 and a conserved IWRXY motif are critical for the function and integrity of the Trf4/5-Air1/2-Mtr4 polyadenylation (TRAMP) RNA quality control complex. J. Biol. Chem. 286, 37429 37445 .

Feuer, G., and Green, P. L. (2005). Comparative biology of human T-cell lymphotropic virus type 1 (HTLV-1) and HTLV-2. Oncogene 24, 59966004.

Franchini, G. (1995). Molecular mechanisms of human T-cell leukemia/lymphotropic virus type I infection. Blood 86, 3619-3639.

Franchini, G., Fukumoto, R., and Fullen, J. R. (2003). T-cell control by human T-cell leukemia/lymphoma virus type 1. Int. J. Hematol. 78, 280-296.

Gallo, R. C. (2005). The discovery of the first human retrovirus: HTLV-1 and HTLV-2. Retrovirology 7, 1-7.

Gareau, J. R., and Lima, C. D. (2010). The SUMO pathway: emerging mechanisms that shape specificity, conjugation and recognition. Nat. Rev. Mol. Cell Biol. 11, 861-871.
Ghorbel, S., Sinha-Datta, U., Dundr, M. Brown, M., Franchini, G., and Nicot, C. (2006). Human T-cell leukemia virus type I p30 nuclear/nucleolar retention is mediated through interactions with RNA and a constituen of the $60 \mathrm{~S}$ ribosomal subunit. J. Biol. Chem. 281, 37150-37158.

Green, P. L., and Chen, I. S. Y. (1990). Regulation of human T cell leukemia expression. FASEB J. 4, 169-174.

Gröne, M., Koch, C., and Grassmann, R. (1996). The HTLV-1 Rex protein induces nuclear accumulation of unspliced viral RNA by avoiding intron excision and degradation. Virology 218, 316-325.

Hakata, Y., Umemoto, T., Matsushita, S., and Shida, H. (1998). Involvement of human CRM1 (exportin 1) in the export and multimerization of the Rex protein of human T-cell leukemia virus type 1. J. Virol. 72, 6602-6607.

Hakata, Y., Yamada, M., and Shida, H. (2001). Rat CRM1 is responsible for the poor activity of human T-cell leukemia virus type 1 Rex protein in rat cells. J. Virol. 75, 11515-11525.

Hamaia, S., Casse, H., Gazzolo, L., and Duc Dodon, M. (1997). The human T-cell leukemia virus type 1 Rex regulatory protein exhibits an impaired functionality in human lymphoblastoid Jurkat t cells. J. Virol. 71, 85148521.

Hanly, S. M., Rimsky, L. T., Malim, M. H., Kim, J. H., Hauber, J., Duc Dodon, M., Le, S. Y., Maizel, J. V., Cullen, B. R., and Greene, W. C. (1989). Comparative analysis of the HTLV-I Rex and HIV-1 Rev trans-regulatory proteins and their RNA response elements. Genes Dev. 3, 1534-1544.

Hidaka, M., Inoue, J., Yoshida, M., and Seiki, M. (1988). Post-transcriptional regulator (rex) of HTLV-1 initiates expression of viral structural proteins but suppresses expression of regulatory proteins. EMBO J. 7, 519-523.

Inoue, J., Seiki, M., and Yoshida, M. (1986). The second pX product $\mathrm{p} 27$ chi-III of HTLV-1 is required for gag gene expression. FEBS Lett. 209 187-190.

Inoue, J., Yoshida, M., and Seiki, M. (1987). Transcriptional (p40x) and post-transcriptional (p27x-III) regulators are required for the expression and replication of human T-cell leukemia virus type I genes. Proc. Natl. Acad. Sci. U.S.A. 84 3653-3657.

Johnson, J. M., Harrod, R., and Franchini, G. (2001). Molecular biology and pathogenesis of the human T-cell leukaemia/lymphotropic virus Type1 (HTLV-1). Int. J. Exp. Pathol. 82, 135-147.
Kadaveru, K., Vyas, J., and Schiller, M. R. (2009). Viral infection and human disease - insights from minimotifs. Front. Biosci. 13, 6455-6471.

Kanamori, H., Kodama, T., Matsumoto, A., Itakura, H., and Yazaki, Y. (1994). Stabilization of interleukin-2 receptor $\alpha$ chain mRNA by HTLV-1 rex in mouse L cells: lower amont of Rex do not stabilize the mRNA. Biochem. Biophys. Res. Commun. 198, 243-250.

Kanamori, H., Suzuki, N., Nosaka, T., and Sato, A. (1990). HTLV-1 p27rex stabilizes human interleukin2 receptor $\alpha$ chain mRNA. EMBO J. 9, 4161-4166.

Kannian, P., and Green, P. L. (2010) Human $\mathrm{T}$ lymphotropic virus type 1 (HTLV-1): molecular biology and oncogenesis. Viruses 2, 2037-2077.

Kashanchi, F., and Brady, J. N. (2005). Transcriptional and posttranscriptional gene regulation of HTLV-1. Oncogene 24, 5938-5951.

Kesic, M., Doueiri, R., Ward, M. Semmes, O. J., and Green, P. L. (2009a). Phosphorylation regulates human T-cell leukemia virus type 1 Rex function. Retrovirology 6, 105.

Kesic, M., Ward, M., Semmes, O. J., and Green, P. L. (2009b). Sitespecific phosphorylation regulates human T-cell leukemia virus type 2 Rex function in vivo. J. Virol. 83, 8859-8868.

Kim, J. M., Song, J. S., Cho, H. H., Shin, K. K., Bae, Y. C., Lee, B. J., and Jung, J. S. (2011). Effect of the modulation of leucine zipper tumor suppressor 2 expression on proliferation of various cancer cells functions as a tumor suppressor. Mol. Cell. Biochem. 346, 125-136.

King, J. A., Bridger, J. M., Lo, M., Lichter, P., and Schulz, T. F. (1998). Nucleocytoplasmic transport of HTLV-1 RNA is regulated by two independent LTR encoded nuclear retention elements. Oncogene 16, 3309-3316.

Kiyokawa, T., Seiki, M., Iwashita, S., Imagawa, K., Shimizu, F., and Yoshida, M. (1985). T-cell leukemia virus type I p27X-III and p21x-III, proteins encoded by the $\mathrm{pX}$ sequence of human T-cell leukemia virus type I. Proc. Natl. Acad. Sci. U.S.A. 82, 8359-8363.

Koralnik, I. J., Fullen, J., and Franchini, G. (1993). The p12I, p13II, and p30II proteins encoded by human T-cell leukemia/lymphotropic virus type I open reading frames I and II are localized in three different cellular compartments. J. Virol. 67, 23602366.

Krainer, A. R., Mayeda, A, Kozak, D., and Binns, G. (1991). Functional 
expression of cloned human splicing factor SF2: homology to RNAbinding proteins, $\mathrm{U} 170 \mathrm{~K}$, and Drosophila splicing regulators. Cell 66, 383-394.

Kress, E., Baydoun, H. H., Bex, F., Gazzolo, L., and Duc Dodon, M. (2005). Critical role of hnRNP Al in HTLV-1 replication in human transformed $\mathrm{T}$ lymphocytes. Retrovirology 2, 8 .

Li, M., Kannian, P., Yin, H., Kesic, M., and Green, P. L. (2012). Human T lymphotropic virus type 1 regulatory and accessory gene transcript expression and export are not Rex dependent. AIDS Res. Hum. Retroviruses 28 , 405-410.

Li, M., Kesic, M., Yin, H., Yu, L., and Green, P. L. (2009). Kinetic analysis of human T-cell leukemia virus type 1 gene expression in cell culture and infected animals. J. Virol. 83 , 3788-3797.

Malik, P., Tabarraei, A., Kehlenbach, R. H., Korfali, N., Iwasawa, R., Graham, S. V., and Schirmer, E. C. (2012). Herpes simplex virus ICP27 protein directly interacts with the nuclear pore complex through NUP62, inhibiting host nucleocytoplasmic transport pathways. J. Biol. Chem. 287, 12277-12292.

Malim, M. H., Hauber, J., Fenrick, R., and Cullen, B. R. (1988). Immunodeficiency virus rev trans-activator modulates the expression of the viral regulatory genes. Nature 335, 181-183.

Matsuoka, M., and Jeang, K.-T. (2007). Human T-cell leukaemia virus type 1 (HTLV-1) infectivity and cellular transformation. Nat. Rev. Cancer 7 , 270-280.

Matsuoka, M., and Jeang, K.-T. (2011). Human T-cell leukemia virus type 1 (HTLV-1) and leukemic transformation: viral infectivity, Tax, $\mathrm{HBZ}$ and therapy. Oncogene 30, 1379-1389.

Michael, B., Nair, A. M., Datta, A., Hiraragi, H., Ratner, L., and Lairmore, M. D. (2006). Histone acetyltransferase (HAT) activity of p300 modulates human $\mathrm{T}$ lymphotropic virus type 1 p30II-mediated repression of LTR transcriptional activity. Virology 354, 225-239.

Monette, A., Panté, N., and Mouland, A. J. (2011). HIV-1 remodels the nuclear pore complex. J. Cell Biol. 193, 619-631.

Nicot, C., Dundr, M., Johnson, J. M., Fullen, J. R., Alonzo, N., Fukumoto, R., Princler, G. L., Derse, D., Misteli, T., and Franchini, G. (2004). HTLV-1-encoded p30II is a post-transcriptional negative regulator of viral replication. Nat. Med. 10, 197-201.
Nicot, C., Harrod, R. L., Ciminale, V., and Franchini, G. (2005). Human T-cell leukemia/lymphoma virus type 1 nonstructural genes and their functions. Oncogene 24, 6026-6034.

Orita, S., Kobayashi, H., Aono, Y., Saiga, A., Maeda, M., and Igarashi, H. (1993). p21X mRNA is expressed as a singly spliced $\mathrm{pX}$ transcript from defective provirus genomes having a partial delection of the pol-env region in human T-cell leukemia virus type 1-infected cells. Nucleic Acid Res. 21, 3799-3807.

Orita, S., Takagi, S., Saiga, A, Minoura, N., Araki, K., Kinoshita, K., Kondo, T., Hinuma, Y., and Igarashi, $\mathrm{H}$. (1992). Human T cell leukaemia virus type 1 p $21 \mathrm{X}$ mRNA: constitutive expression in peripheral blood mononuclear cells of patients with adult T cell leukaemia. J. Gen. Virol. 73, 2283-2289.

Palmeri, D., and Malim, M. H. (1999). Importin $\beta$ can mediate the nuclear import of an arginine-rich Nuclear Localization Signal in the absence of Importin $\alpha$. Mol. Cell. Biol. 19, 1218-1225.

Picard, C., Gabert, J., Olive, D., and Collette, Y. (2004). Altered splicing in hematological malignancies reveals a tissue-specific translational block of the Src-family tyrosine kinase fyn brain isoform expression. Leukemia 18, 1737-1739.

Poiesz, B. J., Ruscetti, F. W., Gazdar, A. F., Bunn, P. A., Minna, J. D., and Gallo, R. C. (1980). Detection and isolation of type $\mathrm{C}$ retrovirus particles from fresh and cultured lymphocytes of a patient with cutaneous T-cell lymphoma. Proc. Natl. Acad. Sci. U.S.A. 77, 7415-7419.

Poiesz, B. J. Ruscetti, F. W., Reitz, M. S., Kalyanaraman, V. S., and Gallo, R. C. (1981). Discovery of new type C retrovirus (HTLV-1). Nature 294, 268-271.

Pollard, V. W., and Malim, M. H. (1998). The HIV-1 Rev protein. Annu. Rev. Microbiol. 52, 491-532.

Popovic, M., Reitz, M. S. Jr., Sarngadharan, M. G., Robert-Guroff, M., Kalyanaraman, V. S., Nakao, Y., Miyoshi, I., Minowada, J., Yoshida, M., Ito, Y., and Gallo, R. C. (1982). The virus of Japanese adult T-cell leukemia is a member of the human T-cell leukemia virus group. Nature 300, 63-66.

Popovic, M., Sarin, P. S., RobertGurroff, M., Kalyanaraman, V. S., Mann, D., Minowada, J., and Gallo, R. C. (1983). Isolation and transmission of human retrovirus (human t-cell leukemia virus). Science 219 , 856-859.
Powell, D. M., Amaral, M. C., Wu, J. Y., Maniatis, T., and Greene, W. C. (1997). HIV Rev-dependent binding of SF2/ASF to the Rev response element: possible role in Rev-mediated inhibition of HIV RNA splicing. Proc. Natl. Acad. Sci. U.S.A. 94, 973-978.

Princler, G. Julias, J. G., Hughes, S. H., and Derse, D. (2003). Roles of viral and cellular proteins in the expression of alternatively spliced HTLV-1 pX mRNAs. Virology 317, 136-145.

Prooyen, N. V., Andresen, V., Gold, H., Bialuk, I., Pise-Masison, C., and Franchini, G. (2010a). Hijacking the Tcell communication network by the human T-cell leukemia/lymphoma virus type 1 (HTLV-1) p12 and p8 proteins. Mol. Aspects Med. 31, 333-343.

Prooyen, N. V., Gold, H., Andresen, V., Schwartz, O., Jones, K., Ruscetti, F. Lockettf, S., Gudlag, P., Venzonh, D., and Franchini, G. (2010b). Human T-cell leukemia virus type 1 p 8 protein increases cellular conduits and virus transmission. Proc. Natl. Acad. Sci. U.S.A. 107, 20738-20743.

Rende, F. Cavallari, I., Corradin, A. Silic-Benussi, M., Toulza, F., Tof folo, G. M., Tanaka, Y., Jacobson, S., Taylor, G. P., D’Agostino, D. M., Bangham, C. R. M., and Ciminale, V. (2011). Kinetics and intracellular compartmentalization of HTLV-1 gene expression: nuclear retention of HBZ mRNAs. Blood 117, 4855-4859.

Rende, F., Cavallari, I., Romanelli, M. G., Diani, E., Bertazzoni, U., and Ciminale, V. (2012). Comparison of the genetic organization, expression strategies and oncogenic potential of HTLV-1 and HTLV-2. Leuk. Res. Treat. 2012, 1-14.

Riley, B. E., Zoghbi, H. Y., and Orr, H. T. (2005). SUMOylation of the polyglutamine repeat protein, ataxin-1, is dependent on a functional nuclear localization signal. J. Biol. Chem. 280, 21942-21948.

Rimsky, L., Hauber, J., Dukovich, M., Malim, M. H., Langlois, A., Cullen, B. R., and Greene, W. C. (1988). Functional replacement of the HIV-1 rev protein by the HTLV-1 rex protein. Nature 335, 738-740.

Rual, J., Venlkatesan, K., Hao, T. Hirozane-Kishikawa, T., Dricot, A., Li, N., Berriz, G. F., Gibbons, F. D., Dreze, M., Ayivi-Guedehoussou, N., Klitgord, N., Simon, C., Boxem, M., Milstein, S., Rosenberg, J., Goldberg, D. S., Zhang, L. V., Wong, S. L., Franklin, G., Li, S., Albala, J. S., Lim, J., Fraughton, C., Llamosas, E., Cevik, S., Bex, C., Lamesch, P., Sikorski, R., S., Vandenhaute, J., Zoghbi., H. Y., Smolyar, A., Bosak,
S., Sequerra, R., Doucette-Stamm, L., Cusick, M. E., Hill, D. E., Roth, F. P., and Vidal, M. (2005). Towards a proteome-scale map of the human protein-protein interaction network. Nature 437, 1173-1178.

Saiga, A, Aono, Y., Imai, J., Kinoshita, K., Orita, S., and Igarashi, $H$. (1996). Presence of antibodies to p21X and/or p27rex proteins in sera from human $\mathrm{T}$-cell leukemia virus type I-infected individuals. J. Virol. Methods 57, 157-168.

Satou, Y., Yasunaga, J., Yoshida, M., and Matsuoka, M. (2006). HTLV-I basic leucine zipper factor gene mRNA supports proliferation of adult $\mathrm{T}$ cell leukemia cells. Proc. Natl. Acad. Sci. U.S.A. 103, 720-725.

Satou, Y., Yasunaga, J., Zhao, T., Yoshida, M., Miyazato, P., Takai, K., Shimizu, K., Ohshima, K., Green, P. L., Ohkura, N., Yamaguchi, T., Ono, M., Sakaguchi, S., and Matsuoka, M. (2011). HTLV-1 bZIP factor induces T-cell lymphoma and systemic inflammation in vivo. PLoS Pathol. 7, e1001274. doi: 10.1371/journal.ppat.1001274

Seeler, J. S., and Dejean, A. (2001). SUMO: of branched proteins and nuclear bodies. Oncogene 20, 72437249 .

Seiki, M., Hattori, S., Hirayama, Y., and Yoshida, M. (1983). Human adult T-cell leukemia virus: complete nucleotide sequence of the provirus genome integrated in leukemia cell DNA. Proc. Natl. Acad. Sci. U.S.A. 80, 3618-3622.

Seiki, M., Hikikoshi, A., and Yoshida, M. (1990). The U5 sequence is a cisacting repressive element for genomic RNA expression of human $\mathrm{T}$ cell leukemia virus type I. Virology 86 , 81-86.

Silic-Benussi, M., Biasiotto, R., Andresen, V., Franchini, G., D’Agostino, D. M., and Ciminale, V. (2010a). HTLV-1 p13, a small protein with a busy agenda. Mol. Aspects Med. 31, 350-358.

Silic-Benussi, M., Marin, O., Biasiotto, R., D’Agostino, D. M., and Ciminale, V. (2010b). Effects of human T-cell leukemia virus type 1 (HTLV-1) p13 on mitochondrial $\mathrm{K}+$ permeability: a new member of the viroporin family? FEBS Lett. 584, 2070-2075.

Simonis, N., Rual, J., Lemmens, I., Boxus, M., Hirozane-Kishikawa, T., Gatot, J., Dricot, A., Hao, T., Vertommen, D., Legros, S., Daakour, S., Klitgord, N., Martin, M., Willaert, J., Dequiedt, F., Navratil, V., Cusick, M. E., Burny, A., Van Lint, C., Hill, D. E., Tavernier, J., Kettmann, R., Vidal, M., and Twizere, J. (2012). Hostpathogen interactome mapping for 
HTLV-1 and 2 retroviruses. Retrovirology $9,26$.

Sinha-Datta, U., Datta, A., Ghorbel, S., Duc Dodon, M., and Nicot, C. (2007). Human T-cell lymphotrophic virus type I rex and p30 interactions govern the switch between virus latency and replication. J. Biol. Chem. 282, 14608-14615.

Solmaz, S. R., Chauhan, R., Blobel, G., and Melčák, I. (2011). Molecular architecture of the transport channel of the nuclear pore complex. Cell 147, 590-602.

Solomin, L., Felber, B. K., and Pavlakis, G. N. (1990). Different sites of interaction for Rev, Tev, and Rex proteins within the Rev-responsive element of human immunodeficiency virus type 1. J. Virol. 64, 6010-6017.

Suhasini, M., and Reddy, T. R. (2009). Cellular proteins and HIV1 Rev function. Curr. HIV Res. 7, 91-100.

Takatsuki, K. (2005). Discovery of adult T-cell leukemia. Retrovirology 3 , $1-3$.

Tange, T. O., Jensen, T. H., and Kjems, J. (1996). In vitro interaction between human immunodeficiency virus type 1 Rev protein and splicing factor ASF/SF2-associated protein, p32. J. Biol. Chem. 271, 10066-10072.

Taylor, J. M., and Nicot, C. (2008). HTLV-1 and apoptosis: role in cellular transformation and recent advances in therapeutic approaches. Apoptosis 13, 733-747.
Theis, C., Reeder, J., and Giegerich, R. (2008). KnotInFrame: prediction of -1 ribosomal frameshift events. Nucleic Acid Res. 36, 6013-6020.

Truant, R., and Cullen, B. R. (1999). The arginine-rich domains present in human immunodeficiency virus type 1 Tat and Rev function as direct Importin $\beta$-dependent nuclear localization signals. Mol. Cell. Biol. 19, 1210-1217.

Vandamme, A.-M., Salemi, M., and Desmyter, J. (1998). The simian origins of the pathogenic human T-cell lymphotropic virus type I. Trends Microbiol. 6, 477-483.

Venkatesan, K., Rual, J., Vazquez, A., Stelzl, U., Lemmens, I., Hirozanekishikawa, T., Hao, T., Zenkner M., Xin, X., Goh, K., Yildirim, M. A., Simonis, N., Heinzmann, K. Gebreab, F., Sahalie, J. M., Cevik, S., Simon, C., de Smet, A., Dann, E., Smolyar, A., Vinayagam, A., Yu, H., Szeto, D., Borick, H., Dricot, A., Klitgord, N., Murray, R. R., Lin C., Lalowski, M., Timm, J., Rau, K., Boone, C., Braun, P., Cusick, M. E. Roth, F. P., Hill, D. E., Tavernier, J., Wanker, E. E., Barabasi, A., and Vidal M. (2009). An empirical framework for binary interactome mapping. Nat. Methods 6, 83-90.

Weil, R., Levraud, J. P., Duc Dodon, M., Bessia, C., Hazan, U., Kourilsky, P., and Israél, A. (1999). Altered expression of tyrosine kinases of the Src and Syk families in human T-cell leukemia virus type 1 -infected T-cell lines. J. Virol. 73, 3709-3717.

White, K. N., Nosaka, T., Kanamori, H., Hatanaka, M., and Honjo, T. (1991). The nucleolar localisation signal of the HTLV-I protein p27rex is important for stabilisation of IL-2 receptor $\alpha$ subunit mRNA by p27rex. Biochem. Biophys. Res. Commun. 175, 98-103.

Wimmer, P., Schreiner, S., and Dobner, T. (2012). Human pathogens and the host cell SUMOylation system. $J$. Virol. 86, 642-654.

Xie, L., Kesic, M., Yamamoto, B., Li, M., Younis, I., Lairmore, M. D., and Green, P. L. (2009). Human T-cell leukemia virus type 2 Rex carboxy terminus is an inhibitory/stability domain that regulates Rex functional activity and viral replication. J. Virol. $83,5232-5243$.

Yoneda, Y. (2000). Nucleocytoplasmic protein traffic and its significance to cell function. Genes Cells 5, 777-787.

Yoshida, M., Miyoshi, I., and Hinuma Y. (1982). Isolation and characterization of retrovirus from cell lines of human adult T-cell leukemia and its implications in the disease. Proc. Natl. Acad. Sci. U.S.A. 79, 2031-2035.

Younis, I., and Green, P. L. (2005). The human t-cell leukemia virus Rex protein. Front. Biosci. 10, 431-445.

Zapp, M. L., Hope, T. J., Parslow, T. G. and Green, M. R. (1991). Oligomerization and RNA binding domains of the type 1 human immunodeficiency virus Rev protein: a dual function for an arginine-rich binding motif. Proc. Natl. Acad. Sci. U.S.A. 88, 7734-7738. Zemmel, R. W., Kelley, A. C., Karn, J., and Butler, P. J. (1996). Flexible regions of RNA structure facilitate co-operative Rev assembly on the Rev-response element. J. Mol. Biol. 258, 763-777.

Conflict of Interest Statement: The authors declare that the research was conducted in the absence of any commercial or financial relationships that could be construed as a potential conflict of interest.

Received: 03 July 2012; accepted: 24 August 2012; published online: 06 September 2012.

Citation: Nakano $K$ and Watanabe $T$ (2012) HTLV-1 Rex: the courier of viral messages making use of the host vehicle. Front. Microbio. 3:330. doi: 10.3389/ fmicb.2012.00330

This article was submitted to Frontiers in Virology, a specialty of Frontiers in Microbiology.

Copyright (c) 2012 Nakano and Watanabe. This is an open-access article distributed under the terms of the Creative Commons Attribution License, which permits use, distribution and reproduction in other forums, provided the original authors and source are credited and subject to any copyright notices concerning any third-party graphics etc. 